OPEN ACCESS

Edited by:

Wenzhong Li,

Freie Universität Berlin, Germany

Reviewed by:

Peng Xue,

Southwest University, China

Xubo Zhao,

Zhengzhou University, China

*Correspondence:

Qi Kang

kqangel@126.com

Jinfeng Xing

jinfengxing@tju.edu.cn

Specialty section:

This article was submitted to Biomaterials,

a section of the journal

Frontiers in Bioengineering and

Biotechnology

Received: 07 September 2021 Accepted: 08 October 2021

Published: 22 October 2021

Citation:

Du X, Gao Y, Kang Q and Xing J (2021)

Design and Applications of Tumor

Microenvironment-Responsive

Nanogels as Drug Carriers.

Front. Bioeng. Biotechnol. 9:771851.

doi: 10.3389/fbioe.2021.771851

\section{Design and Applications of Tumor Microenvironment-Responsive Nanogels as Drug Carriers}

\author{
Xinjing $D u^{1}$, Yuting $\mathrm{GaO}^{1}$, Qi Kang ${ }^{2 *}$ and Jinfeng Xing ${ }^{1 *}$ \\ ${ }^{1}$ School of Chemical Engineering and Technology, Tianjin University, Tianjin, China, ${ }^{2}$ Department of Cardiology, Tianjin Medical \\ University General Hospital, Tianjin, China
}

In recent years, the exploration of tumor microenvironment has provided a new approach for tumor treatment. More and more researches are devoted to designing tumor microenvironment-responsive nanogels loaded with therapeutic drugs. Compared with other drug carriers, nanogel has shown great potential in improving the effect of chemotherapy, which is attributed to its stable size, superior hydrophilicity, excellent biocompatibility, and responsiveness to specific environment. This review primarily summarizes the common preparation techniques of nanogels (such as free radical polymerization, covalent cross-linking, and physical self-assembly) and loading ways of drug in nanogels (including physical encapsulation and chemical coupling) as well as the controlled drug release behaviors. Furthermore, the difficulties and prospects of nanogels as drug carriers are also briefly described.

Keywords: nanogels, stimuli-responsive, controlled release, drug delivery, tumor microenvironment

\section{INTRODUCTION}

The use of nanogels as carriers for drugs and other molecules has been extensively studied over the past 2 decades (Raemdonck et al., 2009; Li Y. et al., 2015; Mohammadi et al., 2020; Zhao et al., 2021). Generally, nanogels are defined as 3D sub-micron sized hydrophilic polymer networks formed through physical or chemical cross-linking, exhibiting the comprehensive properties of hydrogels and nanoparticles simultaneously. Physical cross-linking mainly includes hydrophobic interactions, electrostatic interactions, hydrogen bonds, and ionic interactions. Chemical method is to produce covalent bonds during the preparation of nanogels (Neamtu et al., 2017). Researchers define the acceptable nanogel size as $10-1,000 \mathrm{~nm}$, while others have reported the optimal size of nanogel for biomedical applications is less than $200 \mathrm{~nm}$ (Akiyama et al., 2007). Nanogels are able to absorb a large quantity of water. The cross-linking network of nanogels is considered as a matrix to hold the inner liquid medium, while the absorbed water can be regarded as a filter medium for the diffusion of cargoes. Nanogels with negative Zeta potential are beneficial to avoid phagocytosis of the immune system and can resist the adsorption of negatively charged proteins (Xiao et al., 2011; Cuggino et al., 2019). Moreover, the swelling and shrinking behavior of nanogels is considered as an indispensable feature, which promotes the diffusion of loaded drug (Clegg et al., 2020).

With the exploration of controlled drug delivery, many kinds of drug carriers have attracted wide attention, such as liposomes, polymer vesicles, micelles, and microemulsions due to their good performances in prolonging blood circulation and improving therapeutic efficiency (Zhu et al., 2017; Iqbal et al., 2020; Large et al., 2021). As an emerging drug carrier, nanogel shows unique and promising prospects in biomedical field because of its good biocompatibility, high drug loading capacity, stimuli-responsiveness, low toxicity, and biodegradability (Pinelli et al., 2020; Shah et al., 


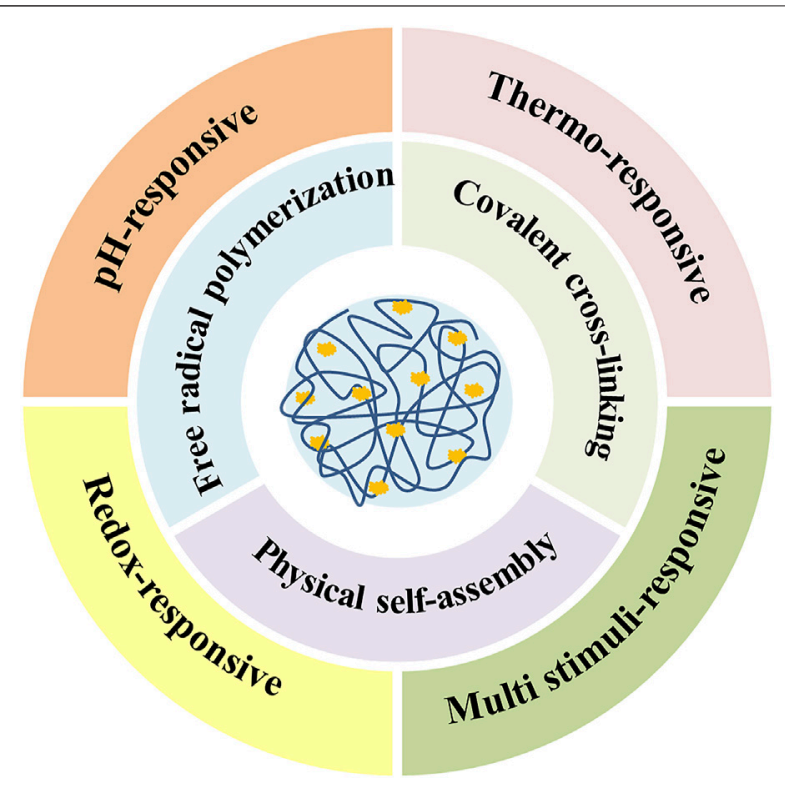

SCHEME 1 | General preparation methods and responsive-release types of drug-loaded nanogels.

2020). In general, an ideal nanogel drug delivery system (NGDDS) should meet the requirements of the entire drug delivery process. Firstly, nanogels are required to effectively load therapeutic drugs and protect them from phagocytosis, elimination, and burst release. Secondly, nanogels should target to the diseased tissues to reduce damage to normal cells. Afterwards, under corresponding stimulus (temperature, $\mathrm{pH}$, magnetic field, light, redox potential, enzymes, etc.), the structures of nanogels are triggered to collapse, swell, or contract to achieve controlled drug release. Finally, the remaining nanogels should be degradable and eliminated from the body with circulation (Xu et al., 2013; Ahmed et al., 2020). Therefore, the design strategies of nanogels as drug carriers include high drug loading content, good biocompatibility, long circulation time, specific ligands recognized by targeted cells, and stimulus-sensitive degradation characteristics.

In recent years, researchers have developed various nanogels with abundant performances. Most nanogels are designed to load therapeutic drugs such as doxorubicin (DOX), curcumin (CUR), methotrexate (MTX), and cisplatin (CDDP), and the others are utilized to deliver nucleic acids, proteins, and genes (Li et al., 2017; Luckanagul et al., 2018a; Lakkakula et al., 2021). So far, the instability of carriers and the presence of various biological barriers are still the main challenges to drug delivery efficiency (Oh et al., 2008; Sharma et al., 2016; Mauri et al., 2018; Hajebi et al., 2019b; Dreiss, 2020). In order to further explore NG-DDS comprehensively and systematically, this review primarily summarizes the synthetic strategies of nanogels (chemical crosslinking and physical crosslinking), methods of drug loading (physical encapsulation and chemical coupling) as well as stimuli-responsive drug release behaviors ( $\mathrm{pH}$, temperature, redox; single, dual, and multi). In addition, according to the development of NG-DDS, major challenges and future prospects of NG-DDS are also depicted (Scheme 1).

\section{GENERAL SYNTHETIC METHODS}

The preparation of nanogels is divided into chemical methods and physical approaches. Chemical methods involve the formation of covalent bonds and the most common technology is the heterogeneous free radical polymerization ( $\mathrm{Li}$ Z. et al., 2019; Mackiewicz et al., 2019; Gurnani and Perrier, 2020). Compared with traditional free radical polymerization, controlled living polymerization could synthesize polymers with specific structures and properties (Gurnani and Perrier, 2020). In order to control the molecular weight, particle size, and particular three-dimensional structure of the polymer, atom transfer radical polymerization (ATRP), reversible addition-fragmentation chain transfer (RAFT), and nitroxide radical polymerization (NMRP) have been widely developed. Besides, the introduction of special cross-linkers into the polymerization system also tends to construct covalently cross-linked nanogels. The decomposition of cross-linkers is beneficial to the degradation of nanogels and controlled drug release in the later stage (Pei et al., 2018). Physical cross-linking means the self-assembly of polymers through weaker interactions, including hydrophobic interactions, supramolecular host-guest assembly, electrostatic interactions, and hydrogen bonds (Wei et al., 2013; Ding et al., 2019b). Comparing these two procedures, the chemical cross-linking shows more permanent and stable connections for the polymer network, whereas physically cross-linked structure is more likely to be destroyed. It is notable that the different crosslinked structures also influence the subsequent ways of drug release. A list of cross-linking mechanisms and corresponding release behaviors of drug-loaded nanogels is shown in Table $\mathbf{1}$.

\section{Free Radical Polymerization}

Most nanogels are prepared by free radical polymerization, which have the advantages of fast reaction speed, high molecular weight of the products, and the increasing of conversion rate with the extension of reaction time (Noordergraaf et al., 2018; Gao et al., 2020). The structures and properties can be adjusted by changing monomer, crosslinking agent, initiator, reaction medium, reaction time, and reaction temperature to achieve optimal drug delivery effect (Ahmed, 2015). Precipitation polymerization, (micro) emulsion polymerization, and dispersion polymerization are common polymerization techniques. Utilizing $\mathrm{N}$-isopropylacrylamide as the monomer, acrylic dendritic polyglycerol as the crosslinking agent, sodium lauryl sulfate as the stabilizer, temperature-sensitive nanogels loading coumarin six were prepared by precipitation polymerization. The results showed that the drug release was thermo-dependent with a remarkable increase above the volume phase transition temperature of $32-37^{\circ} \mathrm{C}$ (Sahle et al., 2017). Sengel prepared a drug carrier with $\mathrm{N}$-(2-mercaptoethyl) acrylamide as a monomer and ethylene glycol dimethacrylate as a cross-linker through dispersion polymerization (Sengel and Sahiner, 2019). Emulsion polymerization means monomers are dispersed in water with the help of emulsifiers and mechanical stirring, and micelles are formed above the critical micelle concentration, where polymer chains keep sustained growth. On this basis, micro (mini) emulsion polymerization and 
TABLE 1 | The preparation mechanisms and relevant drug release behaviors of NG-DDS.

\begin{tabular}{|c|c|c|c|c|c|}
\hline $\begin{array}{l}\text { Network } \\
\text { structure }\end{array}$ & $\begin{array}{l}\text { Cross-linking } \\
\text { mechanism }\end{array}$ & $\begin{array}{l}\text { The nanogel } \\
\text { size }\end{array}$ & $\begin{array}{l}\text { The loaded } \\
\text { molecule }\end{array}$ & $\begin{array}{l}\text { Stimuli- } \\
\text { responsive drug } \\
\text { release }\end{array}$ & References \\
\hline \multirow{4}{*}{$\begin{array}{l}\text { Chemical cross- } \\
\text { linking }\end{array}$} & Traditional free radical polymerization & $90-230 \mathrm{~nm}$ & Doxorubicin & $\mathrm{pH} /$ thermo & Wang et al. (2015) \\
\hline & Controllable/living free radical polymerization & $82-153 \mathrm{~nm}$ & Coumarin 102 & UV light & Xin et al. (2020) \\
\hline & Disulfide, imine cross-linking & $250 \mathrm{~nm}$ & Doxorubicin & $\mathrm{pH} /$ redox & Pei et al. (2018) \\
\hline & Click reaction & $236 \mathrm{~nm}$ & Labeled insulin & Glucose $/ \mathrm{H}_{2} \mathrm{O}_{2}$ & Li et al. (2019a) \\
\hline \multirow{4}{*}{$\begin{array}{l}\text { Physical cross- } \\
\text { linking }\end{array}$} & Hydrophilic and hydrophobic interactions & $55.7-259.2 \mathrm{~nm}$ & Nile Red & $\mathrm{pH}$ & Wang et al. (2018) \\
\hline & Supramolecular host-guest assembly & $108.1-121.4 \mathrm{~nm}$ & $\begin{array}{l}\text { Doxorubicin and indocyanine } \\
\text { green }\end{array}$ & NIR light & Zan et al. (2015) \\
\hline & Hydrophobic/electrostatic interactions & $140-230 \mathrm{~nm}$ & Curcumin & pH/oxidation & Dong et al. (2020) \\
\hline & Hydrogen bonds & $230 \mathrm{~nm}$ & DAPI, fluorescein, Nile red & Thermo & $\begin{array}{l}\text { Zavgorodnya et al. } \\
(2017)\end{array}$ \\
\hline \multirow[t]{3}{*}{ Both } & Disulfide cross-linking/hydrophobic interactions & $66.95 \pm 1.93 \mathrm{~nm}$ & $\begin{array}{l}\text { Purpurin } 18 \text { and 10- } \\
\text { hydroxycamplothecin }\end{array}$ & Redox & Ma et al. (2021) \\
\hline & Free radical polymerization/hydrogen bonds & $18 \mathrm{~nm}$ & Curcumin & Thermo/NIR light & Wang et al. (2014) \\
\hline & $\begin{array}{l}\text { Free radical polymerization/disulfide cross- } \\
\text { linking/ electrostatic interactions }\end{array}$ & $70 \mathrm{~nm}$ & Doxorubicin & $\mathrm{pH} /$ thermo/photo & Chen et al. (2017) \\
\hline
\end{tabular}

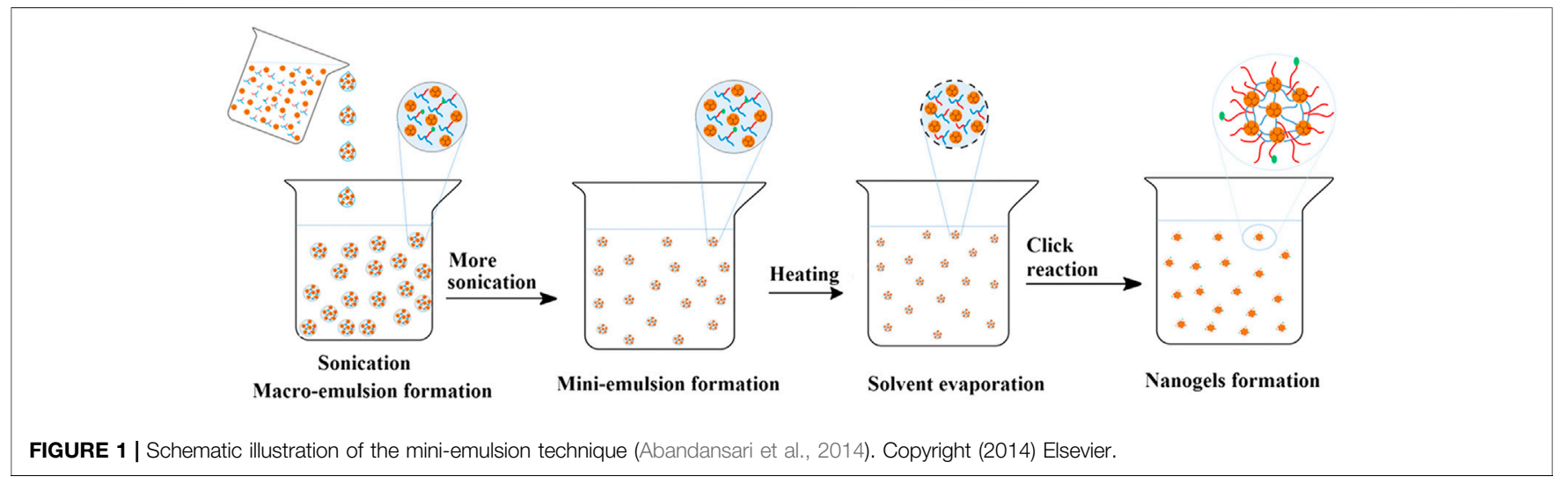

reverse (micro) emulsion polymerization have been developed (Lovell and Schork, 2020; Pereira et al., 2020). The pH-sensitive H40-based nanogels with new structures were synthesized through mini-emulsion polymerization and click reaction (Abandansari et al., 2014). Firstly, the synthesized reactants were added dropwise to the aqueous phase with sonication to obtain the milky macroemulsion. Then the formed macroemulsion was constantly ultrasonicated under ice cooling to form a stable milky miniemulsion. Subsequently, the miniemulsion was heated and catalysts were added to induce the azide-alkyne click reaction and the pure nanogels were collected through dialysis (Figure 1).

With the development of free radical polymerization and controlled drug delivery systems, controllable/living free radical polymerization has attracted much attention (Matyjaszewski and Xia, 2001; Kim et al., 2016; Lou et al., 2017). These prepared polymers have the characteristics of narrow molecular weight distribution and uniform particle size distribution, which facilitate the construction of homogeneous polymer networks and drug loading. ATRP relies on external catalysts (usually transition metal complexs) to reversibly deactivate the free radicals to a dormant state (Matyjaszewski and Xia, 2001). Most of the biodegradable, well-defined and water-dispersed nanogels prepared by ATRP technology occur in reversed micro (mini) emulsions (Siegwart et al., 2009; Averick et al., 2011). The disulfide crosslinked biodegradable nanogels were designed and synthesized employing inverse miniemulsion ATRP (Oh et al., 2007). The releases of encapsulated molecules such as the fluorescent dye rhodamine and the anticancer drug Dox were triggered by the biodegradation of nanogels, demonstrating that these nanogels can be developed as targeted drug delivery carriers for biomedical applications. Compared with ATRP, RAFT with simpler procedures usually uses chain transfer agent (thiocarbonyl compound) rather than poisonous catalysts (Xin et al., 2020). The poly (methyl methacrylate) hair nanoparticles with core-shell structures were prepared through RAFT method. The carriers had high passive drug loading capacity for DOX, exhibiting fast and adjustable drug release behavior at intracellular $\mathrm{pH}(\mathrm{Qu}$ et al., 2017). It is noticeable that although there are lots of merits of controlled living free radical polymerization, these preparations are rarely studied in vivo, and there is little information about biodistribution, clearance and long-term tolerance. 
At present, photo-initiated polymerization has become an effective preparation method due to the short reaction time, mild reaction conditions, and controllable time and space ( $\mathrm{Fu}$ et al., 2015). Messager reported a synthetic method for hyaluronic acid-based nanogels with controllable structures (Messager et al., 2013). Under UV light irradiation, the methacryloyl hyaluronic acid precursor started crosslinking in the droplets of water-in-oil emulsion, which obtained nanoparticles with homogeneous sizes. However, UV radiation may cause potential cell damage, and UV light tends to be scattered by large monomer droplets. Therefore, visible light-induced photopolymerization has been developed because they have longer wavelengths, less scattered by larger objects and better penetration (Matsui et al., 2017; Le Quemener et al., 2018). For example, Bakó prepared nanogels using methacrylic acid poly- $\gamma$-glutamic nanoparticles loading antibiotic drug ampicillin by visible (blue) light-initiated photopolymerization, and the release kinetics showed the controlled and efficient release behaviors (Bakó et al., 2016). Notably, our lab has also developed some strategies on the preparation of nanogels through laser photopolymerization, which is related with the investigation of the initiating system, polymerization mechanism and biomedical applications ( $\mathrm{Li}$ J. et al., 2021; Liu et al., 2021; Peng et al., 2021; Wang et al., 2021). Specifically, Wang chose biocompatible polyethylene glycol diacrylate (PEGDA) as a monomer and ultrasmall nanogels with around $30 \mathrm{~nm}$ in size were prepared successfully through surfactant-free photopolymerization at $532 \mathrm{~nm}$. Subsequently, Li in our lab introduced the third component DPI into the EY/TEOA initiating system, which significantly increased the polymerization rate and conversion ratio, and multifunctional PEGDA hydrogels through a beam expansion device were investigated. Liu's work concentrated on rapid preparation of nanogels through laser beam expansion under low monomer concentration. And the role of triethanolamine in the effect on the cross-linking degree of PEGDA nanogels was investigated by Peng, indicating that triethanolamine could adjust the double-bond conversion.

\section{Covalent Cross-Linking}

The networks of the nanogels can be obtained not only by the polymerization of $\mathrm{C}=\mathrm{C}$ bonds, but also by coupling between other groups. Compounds containing disulfide bonds are one of the most commonly used cross-linking agents, because the disulfide bonds are easily broke by high concentrations of glutathione in tumor tissues and cells to achieve redoxresponsive drug release. For instance, Tian and his coworkers prepared self-assembled hyaluronic acid and polyethylene glycol diglycidyl ether nanogels, then added with cystamine for the second cross-linking and loaded with DOX into the dense networks (Tian et al., 2019). Double cross-linking structures increased the tightness and decreased the burst release of drugs. Besides, the nanogels containing imine bonds formed by aldamine condensation are extensively utilized to deliver drugs due to their good biological activity and acid-sensitivity (Su et al., 2016; Zhao et al., 2017). The modified alginate was coupled with cystamine via disulfide bonds and coupled with DOX via imine bonds, achieving folate receptor-mediated targeting and $\mathrm{pH} /$ reduction dual-responsive drug release (Pei et al., 2018). The cleavage of unstable disulfide bonds and imine triggered the collapse of nanogels, promoting the DOX release and accumulation in the nucleus. In particular, these nanogels exhibited strong fluorescence in acidic media such as the microenvironment of tumor cells, and could be used for realtime, non-invasive positioning and tracking of cancer cells.

In recent years, click chemistry has become a promising strategy for designing nanogels due to its high reactivity, good selectivity, and mild reaction conditions. The thiol-ene click reaction is common in the addition of thiol to the double bonds under photo-initiation, which is efficient, high-yield, and can tolerate different functional groups (Tasdelen et al., 2016; Le et al., 2018; Phan et al., 2020; Mondal et al., 2021). The PEG and polycyclic phenylborate nanogels loaded with insulin and glucose oxidase (Gox) were developed through a one-pot thiol-ene click chemistry method by using tetrathiol compound QT as a coupling agent (Li C. et al., 2019). Since the $\mathrm{H}_{2} \mathrm{O}_{2}$ produced during the oxidation of glucose could cause cytotoxicity, the in-situ consumption of $\mathrm{H}_{2} \mathrm{O}_{2}$ effectively alleviated the side effects of Gox. Compared with nanogels without Gox, nanogels loaded with Gox presented better glucose-responsive abilities and stronger insulin release. These novel glucose $/ \mathrm{H}_{2} \mathrm{O}_{2}$ dual-sensitive nanogels for insulin delivery will be a promising candidate material in the treatment of diabetes in the future. Zhang reported the self-assembly of modified PEG with hydrophobic segments through hydrophilic and hydrophobic interactions and cross-linked with thiols as shown in Figure 2 (Zhang et al., 2019). The loading capacity of nanogels for DOX, gemcitabine, and methotrexate was investigated, showing that all three drugs could be successfully encapsulated inside the nanogels, and delivered to the $3 \mathrm{D}$ pancreatic spheroid tumor model. In summary, many researches have demonstrated that click nanogels with good biocompatibility are very suitable for targeted intracellular drug delivery. However, the current research is still in the preliminary stage. In-depth exploration and reasonable design are necessary to realize true clinical applications.

\section{Physical Self-Assembly}

Compared with chemical cross-linked nanogels, nanogels prepared by physical cross-linking show new functions and have the potential to process, recycle and self-repair due to the nature of dynamic and reversible non-covalent interactions. Usual preparation techniques are to couple hydrophobic segments to hydrophilic polymers, forming amphiphilic macromolecules, and then nanogels will be obtained via selfassembly in aqueous solutions (Chattopadhyay et al., 2016; Thelu et al., 2018; Wang et al., 2018; Wu et al., 2018; Wang et al., 2020). The self-assembled nanogels of ethylene glycol chitosan modified with deoxycholic acid were synthesized, and the diabetic drug palmitoylated exendin-4 (Ex4-C16) was adsorbed on the deoxycholic acid of the chitosan nanogels by hydrophobic interactions (Lee et al., 2012). This kind of drugs could combine with serum albumin to avoid the filtering effect of kidneys and prolong the half-life in the blood. Compared with 


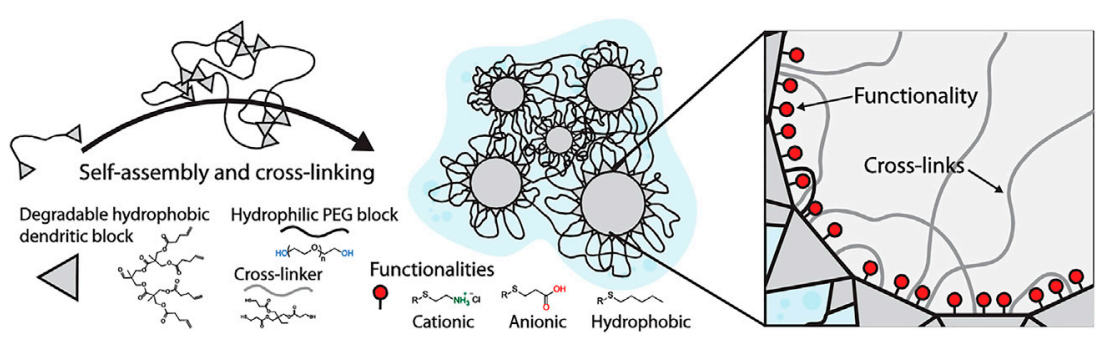

FIGURE 2 | Purposed structure of dendritic nanogels (DNGs) (Zhang et al., 2019). Copyright (2019) John Wiley and Sons.

\section{A}

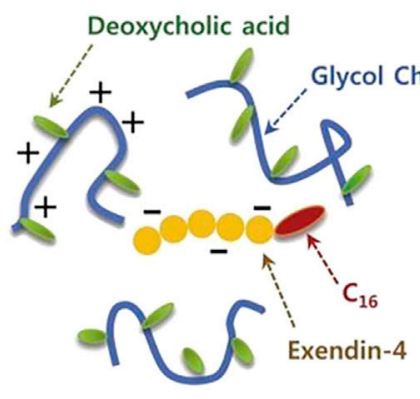

B

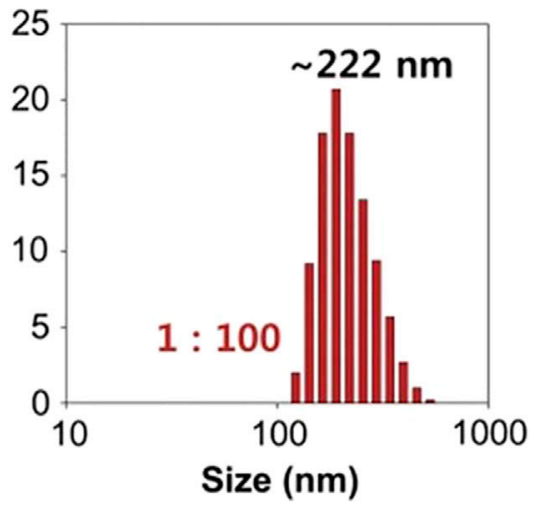

Nanogels Hydrophobic

Selfassembly

C

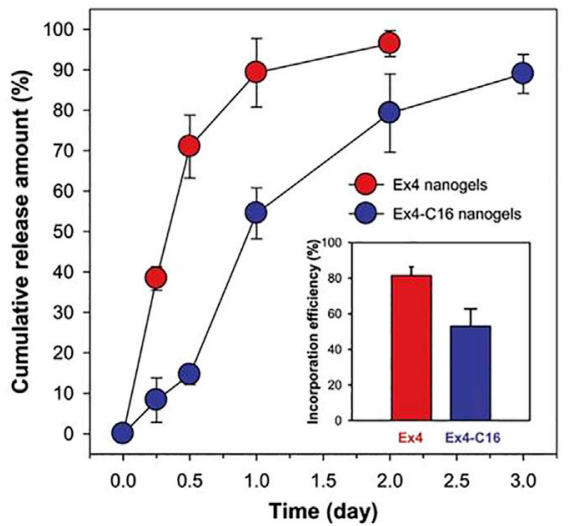

FIGURE 3 | Preparation illustration of nanogels and drug release behaviors. (A) An illustration of self-assembled nanogels; (B) The nanogel particle size distribution with ratio 1:100; (C) Release characteristics of Ex4 and Ex4-C16 from nanogels (Lee et al., 2012). Copyright (2012) Elsevier.

natural Ex4, palmitoylated Ex4 nanogels had lower penetration rate, but the drug release was slower with longer hypoglycemic effects. These nanogels produced hypoglycemia for 2 days in diabetic mice at a relatively low dose $(100 \mathrm{nmol} / \mathrm{kg})$, indicating that the nanogels had long-term hypoglycemic abilities as displayed in Figure 3. In a word, these drug carriers synthesized by hydrophobic interaction are beneficial to the adsorption of hydrophobic drugs, and the interactions between the drugs and carriers can also delay the drug release.

Supramolecular chemistry refers to the chemistry of molecular aggregates based on non-covalent bond interactions between molecules, which primarily studies weak interactions and the assembly, structure, and performance of molecular aggregates (Zan et al., 2015; Qin et al., 2020). Compared with traditional covalently cross-linked nanogels, supramolecular nanogels are easier to adjust their chemical and physical properties by changing the ratio of different components or introducing different stimulus-responsive groups. Common supramolecular host molecules include cyclodextrin, calixarene, crown ether, and hyperbranched polymer (Webber et al., 2016). According to Ding, the phenylalanine grafted chitosan and DOX were wrapped in the cavity of cucurbit(8)urea $[\mathrm{CB}(8)]$ to prepare chitosan nanogels with 


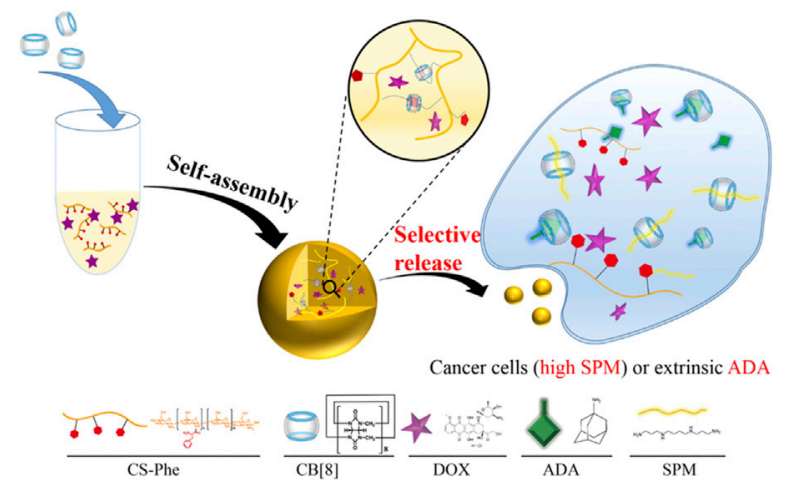

FIGURE 4 | Scheme showing the preparation of host-guest interactioninitiated supramolecular CNGs and their stimuli-responsive payload release in cancer cells (Ding et al., 2019b). Copyright (2019) American Chemical Society.

high drug loading efficiency, good biocompatibility, and selective cytotoxicity against therapeutic targets (Ding et al., 2019a). The CB cavity here functioned as a cross-linking agent, and the self-assembly of macromolecules was realized by wrapping phenylalanine in the cavity. Over-expressed spermine or exogenous stimulus amantadine in tumor cells would replace phenylalanine, because the binding affinity of phenylalanine to $\mathrm{CB}$ (8) was much weaker than that of amantadine or spermine to $\mathrm{CB}$ (8), leading to decrosslinking of nanogels. This kind of drug carriers could respond to specific endogenous or exogenous stimuli to achieve controlled drug release (Figure 4).

Particularly, ionically cross-linked nanogels are provided with better stability than self-assembled nanogels with micellar structures (Perez-Alvarez et al., 2016; Dong et al., 2020). Ionic polysaccharides are commonly used natural macromolecules for the synthesis of nanogels, including chitosan, hyaluronic acid, alginate, etc. (Liang et al., 2015). Nanogels loaded with antitumor drug methotrexate (MTX) were synthesized through ion gel methods using chitosan and sodium tripolyphosphate (TPP) with the small average particle size of $53.34 \pm 7.23 \mathrm{~nm}$, which helped nanogels extend blood circulation time and crossed the blood-brain barriers. After coating the nanogels with polysorbate 80 , the MTX-loaded nanogels showed sustained drug release behaviors (about 65-70\% within $48 \mathrm{~h}$ ). These surface-modified nanogels might be candidates for drug delivery to the central nervous system (Azadi et al., 2012). Besides, alginate could be mixed with cationic poly [(2-dimethylamino) ethyl methacrylate] in water through electrostatic attraction, forming nanogels with size of $150 \mathrm{~nm}$. When loading DOX, the nanogels exhibited acid-accelerated release behaviors as a result of the protonation of DOX and nanogels in an acidic medium, facilitating drug release due to electrostatic repulsion. This preparation method was simple in operation, and had low cost, no organic solvent or additives, good biocompatibility, and controllable drug release, which is beneficial to the drug delivery (Cai et al., 2012).

\section{Microfluidic Technology}

Unlike traditional methods, microfluidic technology has precise fluid control and rapid micro-scale mixing, which has aroused widespread interest in the preparation and engineering of nano-drug delivery materials. Compared with the traditional batch method, the drugloaded nanomaterials prepared by the microfluidics have better monodispersity and their microstructures could be controlled by changing the flow rate and time (Amrani and Tabrizian, 2018; Nie et al., 2019; Zhang et al., 2020). To solve the issues of nanogels as carriers with large size, poor cell uptake rate, and endoplasmic embedding, Huang reported the preparation of HA-based nanogels with particle size of $80-160 \mathrm{~nm}$ via microfluidic technology and tetrazole-olefin light click cross-linking (Huang et al., 2019). The microfluidic chip was made of soda lime glass and nano-droplets formed at the intersection of the three water inlets. Within a certain range, the particle size decreased as the flow rate increasing and the concentration of HA reducing. These carriers could load various therapeutic proteins, such as cytochrome C, herceptin, and BSA with reduction-sensitivity because of the broken of disulfide bonds in the presence of glutathione.

Besides, microfluidic synthesized nanogels could show superior performance in the encapsulation and release of loaded cargoes (Rhee et al., 2011; Feng et al., 2015). For example, the alginate-based and growth factor-loaded nanogels were prepared through ionic gelation using the microfluidic technology (Mahmoudi et al., 2020). An alginate solution mixed TGF- $\beta 3$ as core flow was injected into the microchip, while $\mathrm{CaCl}_{2}$ as the sheath flow was injected into the side channels' inlets of microchip, resulting in the interaction and rapid ionical cross-linking between alginate polymer chains and $\mathrm{Ca}^{2+}$ ions. According to the dynamic light scattering analysis, the microfluidic synthesized nanogels had a smaller diameter and a better polydispersity index $(43 \pm 4 \mathrm{~nm}$, PDI $\leq 0.2)$ than those of the bulk prepared nanogels $(137 \pm 22 \mathrm{~nm}$, PDI $\geq 0.5)$. And the sizes of nanogels would increase with the enhancement of the flow rate ratio, showing a good correlation. Based on the small diameters and compact characteristics of nanogels, the high encapsulation efficiency and slow drug release could be achieved, while the large sizes of the bulk synthesized nanogels caused the low encapsulation efficiency and burst release. Therefore, the nanogels prepared through the microfluidic approach have shown good potential in cargo loading and sustained release.

\section{LOADING WAYS OF DRUG IN NANOGELS}

Loading content refers to the amount of drug loaded per unit weight or unit volume of nanogel, and the amount of drug that can be released is the effective drug loading. An efficient nanocarrier system is required to have high drug loading content, because the drug loading capacity directly affects the clinical application (Sun et al., 2017). The loading methods of carriers include non-covalent and covalent means, namely physical packaging and chemical conjugation. A list of drugloading ways, the encapsulation techniques and corresponding release behaviors of drug-loaded nanogels is shown in Table 2 .

\section{Physical Encapsulation}

Most drugs are loaded in nanogels by non-covalent interactions, including hydrophilic and hydrophobic interactions, hydrogen bonding interactions, and electrostatic interactions, because this method is simple and effective, and does not change the activity of drug molecules (Feng et al., 2010). Among them, the hydrophobic 
TABLE 2 | The drug-loading ways and relevant drug release behaviors of NG-DDS.

\begin{tabular}{|c|c|c|c|c|c|}
\hline $\begin{array}{l}\text { The drug-loading } \\
\text { way }\end{array}$ & $\begin{array}{l}\text { The loaded } \\
\text { drug }\end{array}$ & $\begin{array}{c}\text { The encapsulation } \\
\text { technique }\end{array}$ & $\begin{array}{l}\text { The encapsulation } \\
\text { efficiency }(\%)\end{array}$ & $\begin{array}{c}\text { Stimuli-responsive } \\
\text { drug } \\
\text { release }\end{array}$ & References \\
\hline Physical & Chlorin e6 & The dialysis method & $61.9 \pm 0.15$ & Hyaluronidase & Yoon et al. (2012) \\
\hline \multirow[t]{2}{*}{ encapsulation } & Curcumin & The sonication method & $\begin{array}{l}\text { With } 114 \% \text { loading of curcumin over the } \\
\text { solution }\end{array}$ & Temperature & $\begin{array}{l}\text { Luckanagul et al. } \\
(2018 b)\end{array}$ \\
\hline & Doxorubicin & $\begin{array}{l}\text { Hydrogen-bonded } \\
\text { complexes }\end{array}$ & $82 \pm 4$ & Glutathione & $\begin{array}{l}\text { Senthilkumar et al. } \\
\text { (2019) }\end{array}$ \\
\hline \multirow[t]{3}{*}{ Chemical coupling } & Chlorin e6 & Amidation reaction & $96.23 \pm 4.8$ & - & Lee et al. (2011) \\
\hline & Doxorubicin & Schiff base formation & 32.66 & $\mathrm{pH}$ & Su et al. (2018) \\
\hline & Camptothecin & Esterification reaction & $95.4 \pm 0.9$ (grafting rate) & $\mathrm{pH} /$ redox & Qu et al. (2019) \\
\hline
\end{tabular}

A

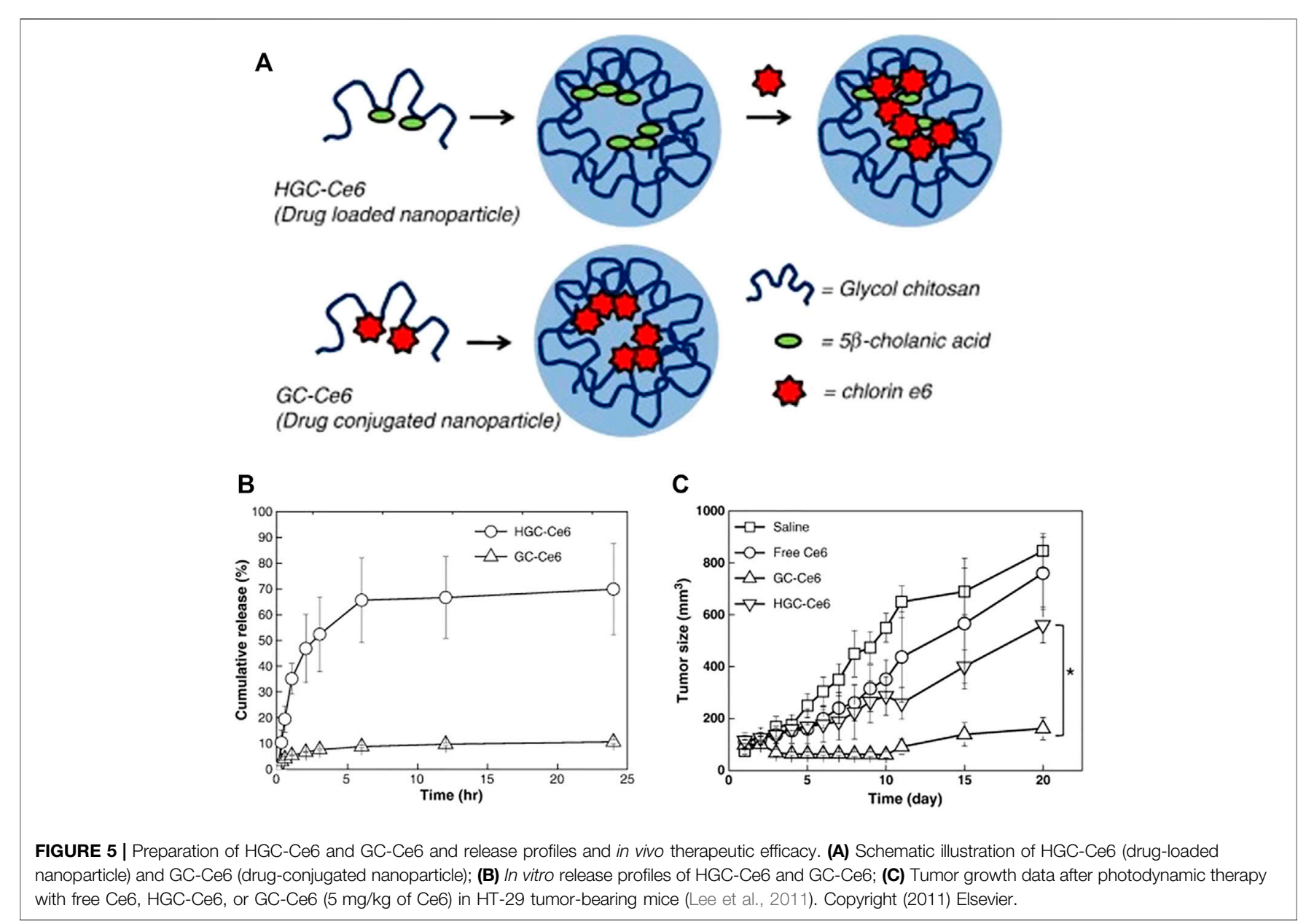

(Drug loaded nanoparticle)

Hyaluronidase

(2018b)

(2019)

$\mathrm{pH} /$ redox

Qu et al. (2019)

interaction is widely applied, because many therapeutic drugs are hydrophobic that can be adsorbed to the hydrophobic center (mainly in the core) of the nanogels. For instance, Yoon prepared hyaluronic acid nanogels coupled with a hydrophobic segment of $5 \beta$-cholanic acid through self-assembly and loaded with chlorin e6 (Ce6) as a hydrophobic photosensitizer with great drug loading content of $80 \%$ (Yoon et al., 2012). At the same time, hydrogen bond-based drug loading is also promising due to directionality, selectivity, and relatively strong interaction, providing drug carriers with stronger drug loading capacity and high physical stability (Li et al., 2018). A novel preparation method of three-hydrogen bonds drug conjugated nanogels was developed (Senthilkumar et al., 2019). The hydrogen bond connection achieved a high drug loading ratio $(82 \pm 4 \%)$, while this number was merely $59 \pm 3 \%$ when drug was loaded through hydrophobic interaction. Importantly, the uniform connection of the hydrogenbonded conjugates in the network assisted the drug to stay in the gel matrix for long time during the circulation. These nanogels had strong stability, good biocompatibility and achieved sustainable drug release for several days. This new strategy of three-point hydrogen 


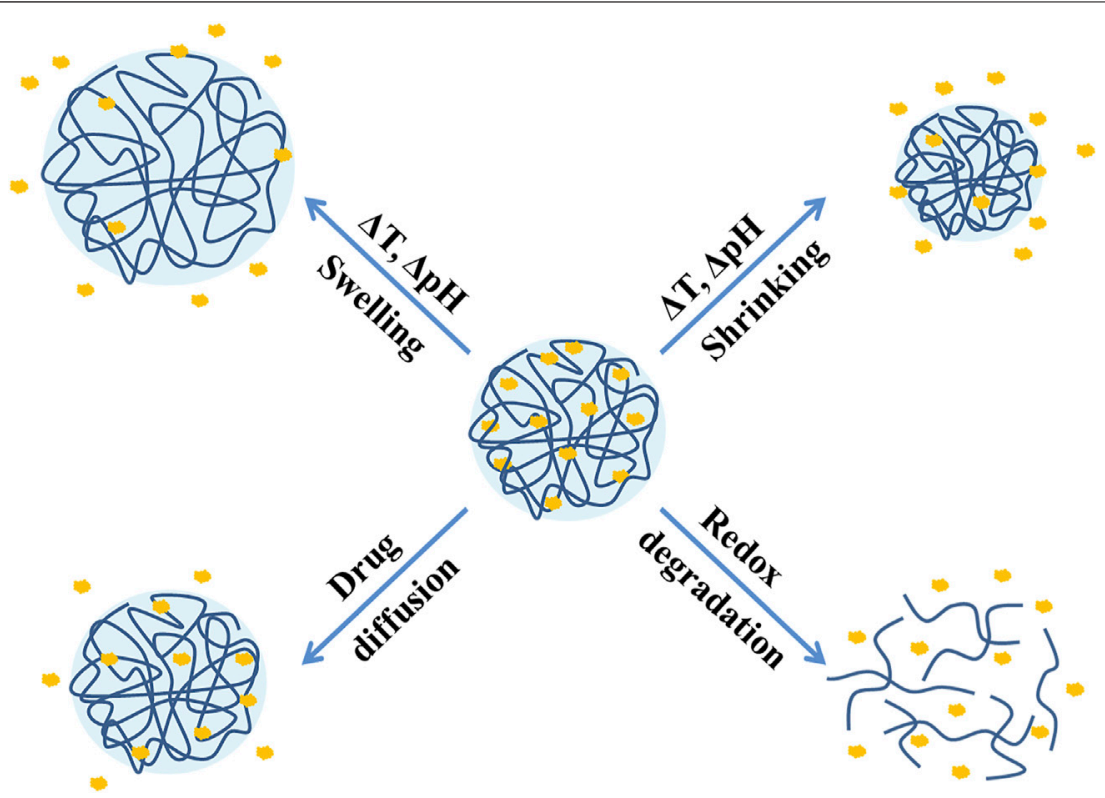

FIGURE 6 | Stimuli-responsive drug release mechanisms of nanogels.

bonds drug coupling could be extended to other carrier systems and various amphiphilic conjugated polymers.

\section{Chemical Coupling}

Physical encapsulation usually leads to inevitable burst release, which reduces the therapeutic effect of drugs (Seidi et al., 2018). To overcome this shortcoming and improve the blood circulation time and accumulation of drugs, covalent coupling has been developed. Lee studied the difference between physical loading and chemical coupling of photosensitizers of tumor-targeted glycol chitosan nanogels as shown in Figure 5 (Lee et al., 2011). On the one hand, the hydrophobic photosensitizer Ce6 was physically loaded into hydrophobically modified carriers. On the other hand, Ce6 was chemically coupled with ethylene glycol chitosan and then nanocarriers were synthesized through self-assembly in aqueous solution. Both nanogels had similar particle sizes and singlet oxygen generation efficiency, but the physical loading exhibited sudden drug release under buffer conditions, where $65 \%$ of drugs were released rapidly within $6.5 \mathrm{~h}$, while the chemical coupling presented longer circulation time and more effective tumor accumulation. When two drug carriers and free Ce6 were injected into tumor-bearing mice, only the chemically coupled carriers showed good phototoxicity, and the tumor volume in mice exhibited sharper reduction than others. The high-efficiency therapeutic effect was probably related to the chemical bond between the drugs and nanogels, indicating that this kind of NGDDS was an effective and promising Ce6 delivery system. In addition, the DOX with active amino groups in the molecules is often coupled to nanogels through Schiff base bond. The $\mathrm{pH}$-sensitive drug-loaded nanogels were obtained through coupling hydroformylated dextran nanogels and DOX (Su et al., 2018). At pH 2.0, 5.0, and 7.4, the drug release amount within $72 \mathrm{~h}$ were about 66,28 , and $9 \%$, while the physically loaded nanogels did not demonstrate acid-accelerated release behaviors. In general, although chemical methods slightly solve the problem of drug burst release, some chemical reactions may also affect the activity and efficacy of drugs. It can be observed that these two drug loading methods have respective advantages and disadvantages.

\section{STIMULI-RESPONSIVE DRUG RELEASE BEHAVIORS}

As mentioned in the first section, an ideal NG-DDS needs to achieve effective drug release at the target site, and the most common release mechanism is drug diffusion (Clegg et al., 2020). In fact, the developments in recent years have shown that regardless of physical embedding or covalent coupling, the current release mechanism tends to be stimuli-responsive release (such as $\mathrm{pH}$, temperature, redox, light, enzymes, etc.), which mainly divides into drug diffusion and swelling, shrinkage, and degradation of nanogels as described in Figure 6. Several stimuli-responsive release systems will be introduced in the following.

\section{pH-Responsive Nanogels}

Designing $\mathrm{pH}$-responsive NG-DDS is one of the most commonly used strategies in tumor treatment, because the weakly acidic $\mathrm{pH}$ ( 6.5) of tumor cells caused by the excessive lactic acid produced by hypoxia is slightly lower than that $(\sim 7.4)$ of normal tissues. Furthermore, the acidic lysosomes in cells ( $\mathrm{pH}$ 5.0-5.5) are also beneficial to the acid-responsive drug release (Li Z. et al., 2021). To obtain acid-sensitive drug carriers, the modification of $\mathrm{pH}$ sensitive molecules and introduction of $\mathrm{pH}$-sensitive bonds (such as acetal bonds, ketal bonds, and imine bonds) into the nanogels are widely used. 
Manchun used glyoxal as a crosslinking agent to synthesize dextrin-based nanogels with acid-sensitive bonds (acetal bond) through emulsion polymerization, loaded with DOX as a model drug, and the drug release behaviors of nanogels with different crosslinking agent content in different $\mathrm{pH}$ were investigated (Manchun et al., 2014). When the molar ratio of dextrin and glyoxal was 20:1, the cumulative release amount was about 40, 94, and $100 \%$ within $72 \mathrm{~h}$ at $\mathrm{pH} 7.4,6.8$, and 5.0, which presented obvious acid-accelerated release behaviors. Under the same $\mathrm{pH}$ conditions, as the increase of molar ratio of dextrin and glyoxal, the release amount was accordingly enhanced, because the content of the crosslinking agent was relevant to the crosslinking density of the nanogels. Afterwards, the author replaced glyoxal with formaldehyde as a crosslinking agent, and exhibited similar acid-responsive drug release (Manchun et al., 2015). Moreover, 2,2-dimethylacryloyloxy-1ethoxypropane (DMAEP) containing ketal bonds was also employed as a pH-labile crosslinking agent. Acid-responsive DOX-loaded nanogels were formed through free radical copolymerization, using acylated $\mathrm{HA}$ as a monomer and DMAEP as a cross-linker, which accelerated the DOX release under acidic conditions (Luan et al., 2017). Borate also has unique acid sensitivity, making borate bonds attractive as driving force for integrated assembly. For example, Zhu reported the selfassembly of dextran and phenylboronic acid-modified cholesterol to synthesize DOX-loaded lysosome-acid targeting drug carriers. At the cellular level, it was clearly demonstrated that lysosomes had a strong influence on the uptake efficiency of nuclear drugs, indicating that lysosomal acidity was the main factor affecting drug efficacy (Zhu et al., 2015).

Currently, nanogels with carboxyl or/and amino groups in the molecular structure are commonly used as $\mathrm{pH}$-responsive drug delivery vehicles. The $\mathrm{pH}$ and thermo sensitive nanogels with DOX loading composed of poly ( $\mathrm{N}$-isopropylacrylamide-coacrylicacid) core, a polydopamine layer and an outer folic acid layer were designed and developed (Pu et al., 2021). With the decrease of $\mathrm{pH}$ from 7.4 to 5.5, the cumulative DOX release amount improved from 17.6 to $56.5 \%$. The enhancement of drug release at $\mathrm{pH} 5.5$ was attributed to the reduction of carboxyl ionization, which induced electrostatic interaction between carboxyl groups as well as the shrinkage of nangels. Moreover, poly (N,N-dimethylaminoethyl methacrylate) (PDMAEMA) is also a $\mathrm{pH}$-sensitive cationic polymer because of protonation of the amino groups when the $\mathrm{pH}$ is lower than $\mathrm{pKa}$ of PDMAEMA (approximately 7.5) (Brannigan and Khutoryanskiy, 2017; Li Z. et al., 2021). Injectable PDMAEMA nanogels were developed through facile precipitation polymerization with in situ thermogelling behaviors and $\mathrm{pH}$-triggered switching activity (Maiti et al., 2018). According to the release profile, the DOX release was acidic dependent from merely $43 \%$ at physiological $\mathrm{pH}$ to around $80 \%$ at $\mathrm{pH} 5.8$ after $96 \mathrm{~h}$ of incubation. On the one hand, the protonation of the amino group resulted in increased electrostatic repulsion, causing the swelling of PDMAEMA nanogels. On the other hand, it might originate from enhanced electrostatic repulsion between quaternized PDMAEMA and positively charged DOX drug molecules, facilitating the DOX release.

\section{Temperature-Sensitive Nanogels}

Another feature of tumors and inflammatory areas is that the temperature $\left(40-45^{\circ} \mathrm{C}\right)$ is slightly higher than that $\left(37^{\circ} \mathrm{C}\right)$ of body fluids, which makes it valuable to design thermo-sensitive nanogels (Seo et al., 2012). Changes in temperature can reverse the segment-segment interaction or the segmentsolvent molecule interaction, resulting in swelling or shrinkage of nanogels to achieve responsive drug release with corresponding temperature of the lower and higher critical solution temperature (LCST/UCST) (Yu et al., 2021).

Poly (N-isopropylacrylamide) (PNIPAAm) is one of the most attractive thermo-sensitive polymers with a low LCST of approximately $32^{\circ} \mathrm{C}$ (Wang et al., 2014). For example, Luckanagul reported the synthesis of chitosan-based nanogels with modification by thermo-sensitive PNIPAM and CUR was successfully loaded through a simple sonication method in aqueous media, showing temperature-responsive drug release behaviors (Luckanagul et al., 2018b). In order to study the influence of the degree of crosslinking and the existence of holes in the nanogels on the drug loading and release characteristics, Hajebi synthesized temperature-responsive hybrid core-shell nanogels using NIPAM and vinyl-modified silica nanoparticles via precipitation polymerization, and hollow PNIPAM nanogels were obtained by hydrolysis of silicic acid (Hajebi et al., 2020). All results demonstrated that the hollow nanogels had higher DOX loading content and higher toxicity, whereas hybrid nanogels showed faster drug release. Both nanogels presented thermo-sensitive drug release behaviors. The above results show that PNIPAM NG-DDS is promising for cancer treatment due to heat-sensitive, non-toxic, and biocompatible. However, their clinical applications are restricted due to hard degradation of PNIPAM in the body.

Other molecules like acrylamide (AAm) and $\mathrm{N}$-vinylcaprolactam (NVCL) are similar with NIPAM, which exhibit temperature sensitive behaviors. The NVCL-based nanogels through self-assembly with poly ( $\mathrm{N}$-vinylpyrrolidone) were successfully prepared, loaded with the non-steroidal antiinflammatory drug diclofenac sodium (Zavgorodnya et al., 2017). The cumulative transporting amount of drug at $32^{\circ} \mathrm{C}$ was 12 times than that at $22^{\circ} \mathrm{C}$, showing excellent temperature-controlled drug release. Theune developed thermo-sensitive polypyrrole nanogels with spherical shape (200 nm of hydrodynamic size) using semiinterpenetrating in-situ polymerization and the obtained nanogels maintained good temperature responsive behaviors in the near-infrared region (Theune et al., 2019). When the MTX was loaded, temperature did not have much effect on the release with the cumulative release amount of $10-15 \%$. However, the release increased significantly with near-infrared radiation, mainly due to that the local heating of the polypyrrole chains weakened the interactions between the drugs and nanogels, causing collapse of nanogels to promote the drug release. Compared with PNIPAM-based nanogels, polypyrrole-based nanogels can be accumulated in multiple intravenous injections without structural collapse at higher temperatures (such as $37^{\circ} \mathrm{C}$ ). Besides, polymers with thermo-sensitivity, such as polyethylene glycol, polyethylene oxide-polypropylene oxide copolymers, poly ( $\varepsilon$-caprolactone), and poly (propylene glycol) 

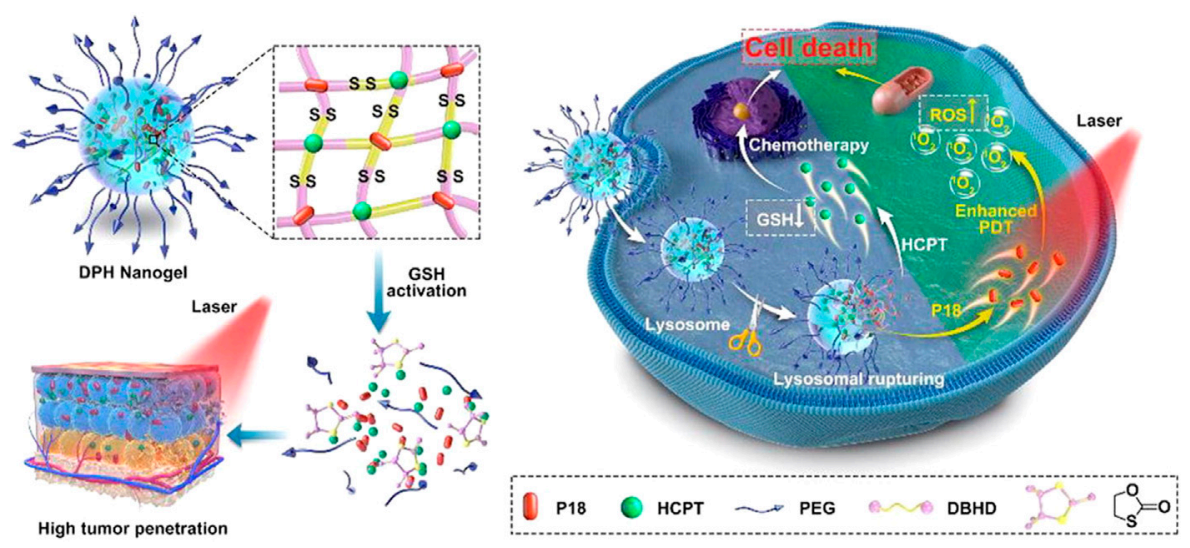

FIGURE 7 | Schematic illustration of redox-responsive prodrug nanogels for combining photodynamic therapy and chemotherapy (Ma et al., 2021). Copyright (2021) Elsevier.

are also expected to be applied to design temperature-dependent nanogels for drug delivery (Yu et al., 2021).

\section{Redox-Sensitive Nanogels}

Due to the high proliferation characteristics of tumor cells, high levels of reactive oxygen species (ROS) are overexpressed in tumor tissues and cells, resulting into high levels of reduced glutathione $(\mathrm{GSH})$ in order to maintain redox homeostasis $(\mathrm{Wu}$, 2006). According to research data, the concentration of GSH in tumor cells reaches $2-10 \mathrm{mM}$, while the concentration in normal tissues is merely around 2-20 $\mathrm{MM}$ (Yuan et al., 2018; Kumar et al., 2019). Based on this, Lu developed a two-in-one cross-linking strategy to prepare GSH-responsive prodrug nanogels by coupling DOX and CPT using disulfide compound as crosslinker agent ( $\mathrm{Lu}$ et al., 2021). Under the high concentration of GSH in tumor, both DOX and CPT released about 75\% within $48 \mathrm{~h}$ in physiological $\mathrm{pH}$ 7.4. Moreover, compared with the single drug, the toxicity of the prodrug nanogels showed significant superiority, indicating the high-performance drug synergetic capacity of this strategy. Similarly, as illustrated in Figure 7, a redox-responsive cross-linker was introduced to synthetize prodrug nanogels based CPT and purpurin 18 (P18) with suitable size $(\sim 67 \mathrm{~nm})$, high drug loading content, controlled drug release, and deep tumor penetration (Ma et al., 2021). According to the release profile, nearly $90 \%$ of CPT released in $10 \mathrm{mM} \mathrm{GSH}$, whereas the cumulative release amount was merely $10 \%$ without GSH in the $\mathrm{pH} 7.4$ PBS solution. Simultaneously, the released P18 could be activated by NIR of $700-900 \mathrm{~nm}$ as a fluorescence imaging agent, demonstrating that nanogels achieved combined photodynamic and chemotherapy as potential drug carrier and diagnostic agent.

Besides disulfide bonds, Se-Se bonds also show stimulusresponsive to redox conditions due to their lower bond energy. More importantly, selenium is an essential trace element for the human body and its anti-cancer activity has been confirmed by anticancer mechanisms and clinical experimental studies (Lanfear et al., 1994; Zhu et al., 1996; Moses et al., 2019). For instance, Li and his coworkers chose sodium diselenide as a crosslinking agent to synthesize nanogels with polyphosphate core and hydrophilic PEG shell (Li C. et al., 2015). The nanogels behaved strong inhibitory effects on the proliferation of the tumor cells, which might be attributed to the cleavage of diselenide bonds in the presence of the over-expressed ROS and GSH in the cancer cell. These nanogels were little toxicity to normal cells, and seemed to be promising and highly effective selfrelease anticancer drug carriers. In addition, the nanogels containing diselenide bonds could also be loaded with other anticancer drugs to achieve combined therapy. For example, the diselenide cross-linked PEG-based nanogels were simply synthesized through physical selfassembly with $32.7 \%$ DOX loading content (Hailemeskel et al., 2018). Experiments showed that the initial release was relatively fast in the first few hours with the presence of $\mathrm{GSH}$ and $\mathrm{H}_{2} \mathrm{O}_{2}$, reaching 52.5 and $54 \%$ at 24 and $48 \mathrm{~h}$, respectively. In the absence of $\mathrm{GSH}$ and $\mathrm{H}_{2} \mathrm{O}_{2}$, the $72 \mathrm{~h}$ release amount was relatively low at $35.6 \%$. Another important feature of Se is that hydrophobic selenide group can be oxidized to hydrophilic selenoxide/selenone groups with the presence of oxidant. The selenium-containing polyphosphoester nanogels as stable and efficient drug carriers were developed by ring-opening polymerization (Zhang et al., 2018). Under the condition of overproduced ROS in cancer cells $(0.05-0.1 \mathrm{mM})$, the average hydrodynamic diameter of nanogels increased from 164 to $400 \mathrm{~nm}$ due to the oxidation of selenide group, which accelerated the efficient intracellular drug release owing to the rapid swelling of nanogels.

\section{External-Stimulus Responsive Nanogels}

The above three stimuli belong to the endogenous stimuli of the tumor microenvironment. In addition, some external stimuli, such as light and magnetic field, are also often used in nanogel drug delivery systems. The UV-light responsive crosslinker 5-(acryloyloxy)-2nitrobenzyl acrylate was introduced into the methoxy polyethylene glycol methacrylate-based nanogels with higher drug loading and encapsulation efficiency, showing good photo-responsive release capability at the $365 \mathrm{~nm}$ ultraviolet light (Xin et al., 2020). Zan developed a near-infrared light-triggered nanogel drug release system based on the advantages of high tissue penetration and low damage. The nanogels loaded with indocyanine green and DOX exhibited superior photo-thermal performance and controlled drug 


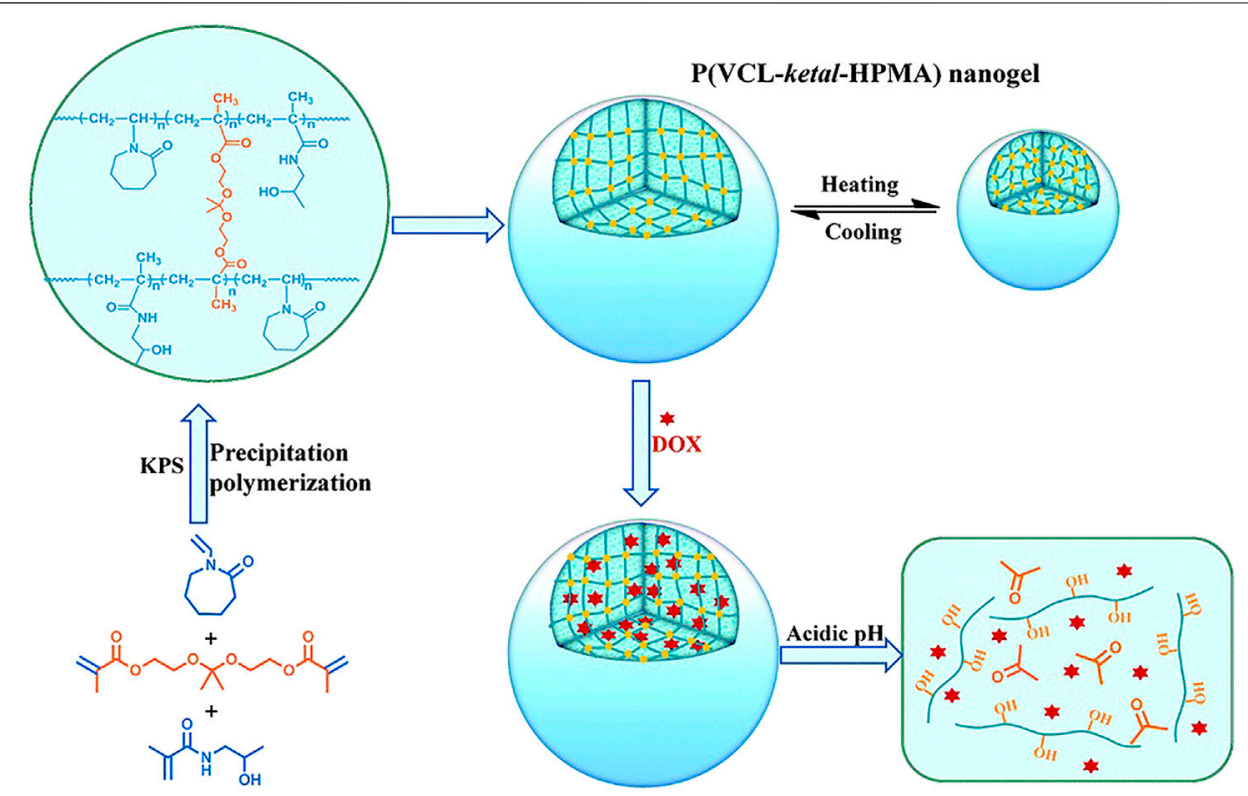

FIGURE 8 | Illustration of the preparation, stimuli-responsive behavior and acid-triggered drug release of the P(VCL-ketal-HPMA) nanogel (Wang et al., 2015). Copyright (2015) Royal Society of Chemistry.

release under NIR laser irradiation (Zan et al., 2015). Besides, the magnetic field-responsive hybrid nanogels have been widely developed recently, which can be attributed to the generation of external heat to kill tumor cells when exposed to a magnetic field. The magnetic/NIR-thermally responsive core-shell hybrid nanogels loaded curcumin were prepared, using bifunctional nanoparticles composed of carbon dot and superparamagnetic nanocrystals cluster as the core and the poly (NIPAM-AAm) as the shell. Both alternating magnetic field and the NIR light irradiation produced local heat, resulting in the shrinkage of poly (NIPAM-AAm) shell and the accelerated release of curcumin. Therefore, the multifunctional hybrid nanogel can be considered as an external stimulus-responsive drug carrier.

\section{Dual/Multi-Stimuli Responsive Nanogels}

At present, the development trend of nanogels as drug carriers is more and more intelligent. Compared with single stimulusresponsive nanogels, the sensitivity and specificity for dual and multiple responsive nanogels to target tumors might be improved (Hajebi et al., 2019a). The physical or chemical properties of these nanogels can be adjusted in response to a stimuli combination of temperature, $\mathrm{pH}$, redox, light, and enzyme to release their cargoes. In this section, we will discuss dual-stimuli and tristimuli responsive nanogels and their release behaviors.

Among various dual-stimuli sensitive nanocarriers, the combination of temperature and $\mathrm{pH}$ is currently the most widely used. In order to reduce the release of cisplatin in $\mathrm{pH}$-responsive nanogels, NIPAM was introduced into nanogels as the thermosensitive unit (Peng et al., 2013). The release of cisplatin in nanogels containing NIPAM was facilitated by $\mathrm{H}^{+}$attack and decreased as the temperature increasing. The results showed that the $\mathrm{pH} /$ temperature dual-responsive nanogels are effective intracellular delivery systems for cisplatin drugs. As mentioned above, ketal and PNVCL are common acid and temperature-sensitive compounds. The $\mathrm{pH} /$ thermo responsive nanogels loaded with DOX were designed through precipitation polymerization using $\mathrm{N}$-(2-hydroxypropyl) methacrylamide and NVCL as copolymer monomers and the ketal as a cross-linking agent as seen in Figure 8. The release of DOX could be accelerated by lowering the $\mathrm{pH}$ and increasing the temperature. Compared with nanogels without ketal agent, the nanogels containing ketal showed obvious acid-dependent release behavior, with a release amount of $13 \%(\mathrm{pH} \mathrm{7.4)}$ and $96 \%(\mathrm{pH} \mathrm{5.0)}$ at $48 \mathrm{~h}$, and higher cytotoxicity and efficiency to kill HeLa cells (Wang et al., 2015).

Due to the presence of high concentrations of GSH in tumor cells and the acidic environment of the lysosome, $\mathrm{pH} / \mathrm{GSH}$ dual-sensitive nanogels provide an effective strategy for delivery and intracellular release of anti-cancer drugs (Chen et al., 2014; Li and Liu, 2018). The $\mathrm{pH} /$ redox dual-responsive nanogels based on NIPAM and acrylic acid with disulfide bonds as the crosslinking agent were prepared by Yang et al. (2016). As shown in Figure 9, when the DOX-loaded nanogels were internalized into the lysosome of tumor cells, they would shrank to partially release DOX, and then disintegrated under the trigger of high intracellular GSH, causing the complete DOX release. Camptothecin (CPT) belongs to plant anticancer drugs, and has good effects on gastrointestinal, head and neck cancers, but its poor water solubility and serious side effects hinder its clinical application (Ulukan and Swaan, 2002; Tai et al., 2014). To solve these, researchers try to modify the prodrug to improve the performance of CPT. For instance, Qu utilized functionalized CPT, methacrylic acid, and N,N'methylenebisacrylamide as raw materials, where CPT was chemically coupled to nanogels through disulfide bonds (Qu et al., 2019). The drug release was $\mathrm{pH}$ and redox dependent, and it accelerated with the increase of GSH level and the decrease of $\mathrm{pH}$ value. At physiological $\mathrm{pH} 7.4$, the cumulative release amount for $48 \mathrm{~h}$ was less than $8.6 \%$. 
<smiles>C=CC(=O)NCCSSCCNC(=O)C=C</smiles>

B NIPAM AA

$\mathrm{BAC}$<smiles>CCC(C)C(=O)NC(C)C</smiles>

Nanogels

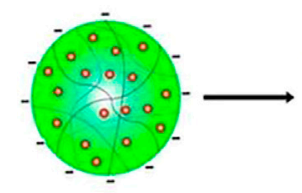

pH 7.4
Nanogels

$\therefore$ DOX

pH 4.5 high GSH

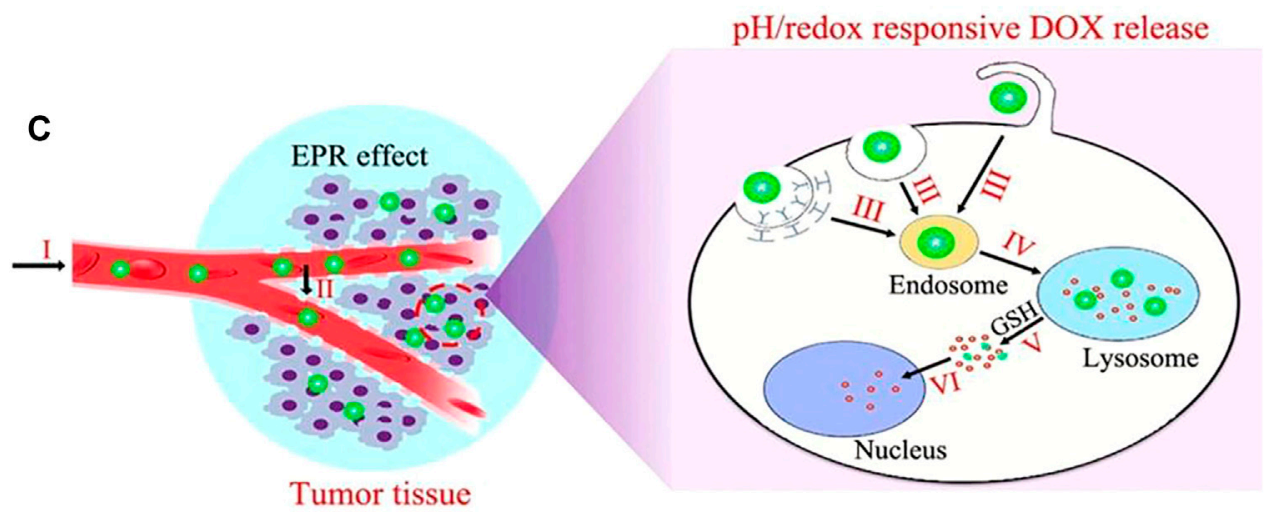

FIGURE 9 | Schematic illustration of P (NIPAM-ss-AA) nanogels for anticancer drug delivery. (A) Construction of P(NIPAM-Ss-AA) nanogels; (B) Characterization of P(NIPAM-ss-AA) nanogels in response to intracellular microenvironment; (C) Site-directed DOX release delivered (Yang et al., 2016). Copyright (2016) American Chemical Society.

However, when the GSH concentration was 2 and $10 \mathrm{mM}$, the $48 \mathrm{~h}$ release amount was 50.9 and $87.7 \%$ under the condition of $\mathrm{pH} 5.0$, respectively. It is beneficial to achievie "on-demand" drug release in the microenvironment of tumor cells and tumor tissues for these nanogels.

Compared with single-responsiveness and double-responsiveness, multi-responsiveness are hopeful to improve the versatility of carriers to meet more practical needs. According to Lou, a $\mathrm{pH} /$ thermo/redox three-stimuli responsive targeted-liver cancer NG-DDS was developed by using functionalized galactose, NVCL, and methacrylic acid as monomers and disulfide bonds compound as a cross-linking agent to encapsulate DOX (Lou et al., 2015). After entering the cancer cells, GSH triggered the cleavage of disulfide bonds and disintegration of nanogels, leading to the release of drugs. PNIPAM was added to the alginate emulsion and cross-linked with cystamine to prepare nanogels with triple-stimuli properties (temperature, $\mathrm{pH}$ and redox sensitivity) (Ji et al., 2017). Under the synergistic effects, the release of DOX was more complete than the release of one or two stimuli, which promoted the tumor-targeting and intracellular delivery characteristics of anticancer drug release.
Besides the above three stimuli system, light stimulation has also attracted much attention due to the rapid development of photodynamic therapy (PDT) and photothermo therapy (PTT). For example, a new type of disulfide cross-linked polyacrylic acidmethyl spiropyran light/pH/redox responsive drug carrier was designed and synthesized, which tended to be isomerization under ultraviolet light or at low $\mathrm{pH}$, and the addition of the reducing agent dithiothreitol caused collapse of nanogels (Chen et al., 2017). The combined stimulation showed synergistic effect on the DOX cumulative release. Multi-responsive PVCL-based nanogels with core/shell structure were synthesized using precipitation polymerization as exhibited in Figure 10 (Li X. et al., 2021). The nanogels could be employed to modify or/and load with various functional agents to construct multi-stimuli responsive nanoplatforms. DOX-loaded nanogels exhibited $\mathrm{pH} / \mathrm{NIR} /$ redox triggered drug release, which achieved DOX release of $59.2 \%$ under $\mathrm{pH} 5.5$ and NIR laser, and the final DOX cumulative release amount reached $79.2 \%$ under $\mathrm{pH} 5.5$ and GSH condition. Remarkably, the combinational therapies are beneficial to the controlled drug release and deeper tissue tumor penetration, 

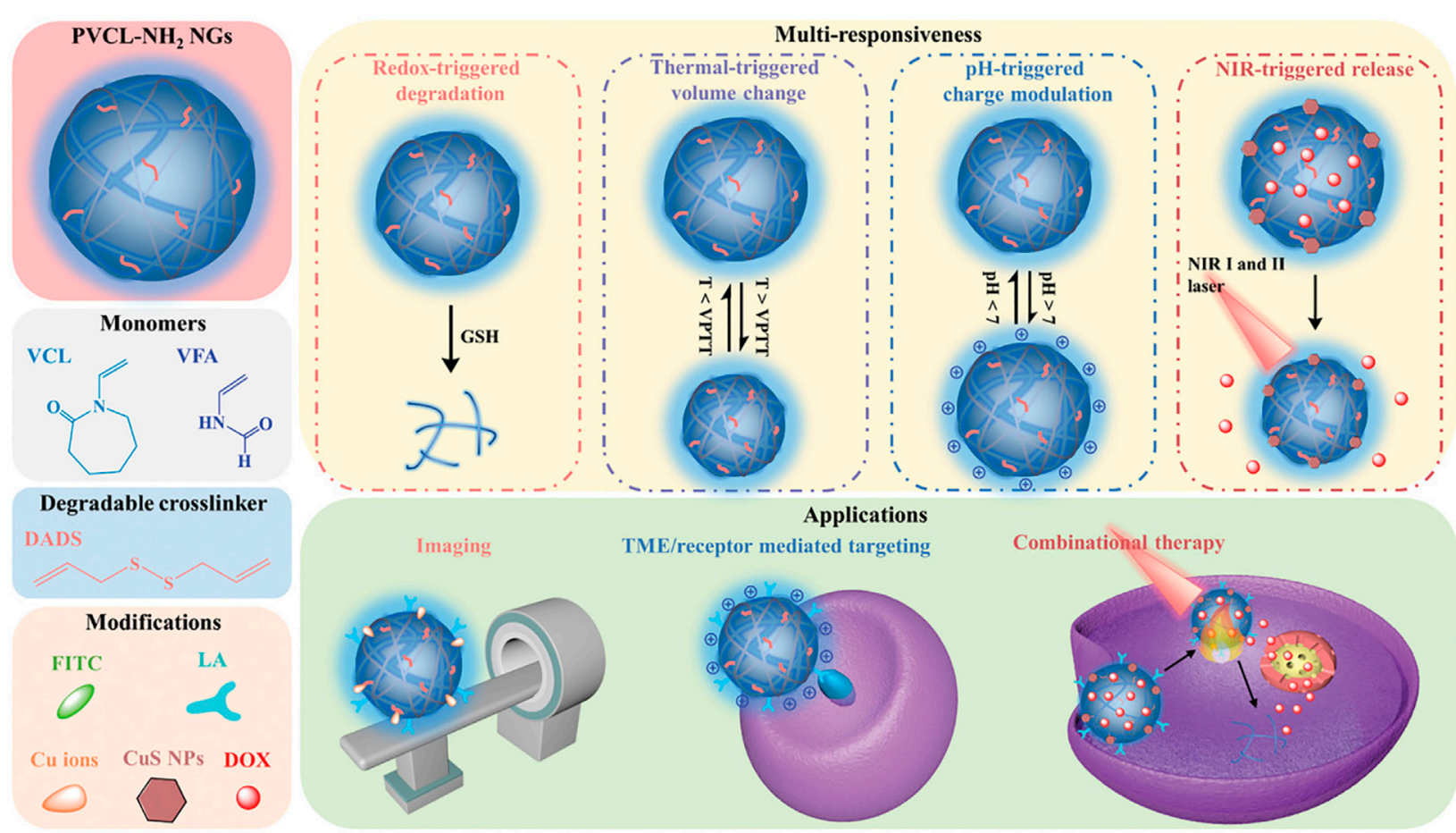

FIGURE 10 | Overview of multi-responsive PVCL-based nanoplatforms (Li X. et al., 2021). Copyright (2021) John Wiley and Sons.

achieving enhanced anticancer efficacy compared with single photothermo therapy and chemotherapy.

\section{MAJOR CHALLENGES AND CONCLUSION}

Although there have been lots of research of NG-DDS, there are still problems and challenges in the actual clinical applications. Firstly, the drug loading content of most nanogels is not always high, leading to the low release amount. Therefore, the structures of carriers are required to be further optimized to load more drugs. Secondly, after the carriers entering the blood circulation, the problem of burst release still exists, resulting in significant reduction of drugs that actually target tissues and cells, which requires the deeper exploration of more intelligent stimulus-responsive nanogels to improve the targeting performance and responsiveness. Thirdly, it is currently recognized that the main factor for the enrichment of nanogels in tumor sites is the EPR effect, namely, the high permeability and retention effect due to the rich blood vessels of tumor tissues and the wide vascular wall gap. However, the research on the EPR effect is currently only at the stage of animal experiments and has not been verified in humans. Fourthly, after administration, nanogels are required to overcome lots of biological barriers, such as mucus, skin, tumor microenvironment, blood-brain barrier, etc. Therefore, it is essential to flexibly change the physical and chemical properties of nanogels or modify the surface of nanogels to overcome different biological barriers.

In general, nanogels have shown promising prospects as drug carriers, and provided great potential for intelligent drug delivery. The strategies for designing nanogels as ideal drug carriers should have high drug loading, long circulation time, specific ligands recognized by target cells, and stimulussensitive degradation characteristics. There is no doubt that drug carriers are beneficial in tumor treatment, such as reducing drug toxicity, improving efficacy, and enhancing patient tolerance. However, nanogel drug delivery systems can truly achieve clinical applications after solving problems mentioned above.

\section{AUTHOR CONTRIBUTIONS}

$\mathrm{XD}$ and YG: conceptualization, investigation and writing-original draft. QK and JX: supervision, writing-reviewing and editing. All authors contributed to the article and approved the submitted version.

\section{FUNDING}

The National Natural Science Foundation of China (31771094).

\section{ACKNOWLEDGMENTS}

Authors thank the support of National Natural Science Foundation of China (31771094) and Tianjin Science and Technology Innovation Platform Program (14TXGCCX00017). 


\section{REFERENCES}

Abandansari, H. S., Nabid, M. R., Rezaei, S. J. T., and Niknejad, H. (2014). pHsensitive nanogels based on Boltorn $\mathrm{H} 40$ and poly(vinylpyridine) using miniemulsion polymerization for delivery of hydrophobic anticancer drugs. Polymer 55, 3579-3590. doi:10.1016/j.polymer.2014.06.037

Adetunji Moses, O., Khan, M. I., Fang, Q., Qin, L., Rehman, Z. U., Zhang, Y., et al. (2019). PVP intercalated metallic WSe2 as NIR photothermal agents for efficient tumor ablation. Nanotechnology 30, 065102. doi:10.1088/1361-6528/ aaf151

Ahmed, E. M. (2015). Hydrogel: Preparation, characterization, and applications: A review. J. Adv. Res. 6, 105-121. doi:10.1016/j.jare.2013.07.006

Ahmed, S., Alhareth, K., and Mignet, N. (2020). Advancement in nanogel formulations provides controlled drug release. Int. J. Pharmaceutics 584, 119435. doi:10.1016/j.ijpharm.2020.119435

Akiyama, E., Morimoto, N., Kujawa, P., Ozawa, Y., Winnik, F. M., and Akiyoshi, K. (2007). Self-Assembled Nanogels of Cholesteryl-Modified Polysaccharides: Effect of the Polysaccharide Structure on Their Association Characteristics in the Dilute and Semidilute Regimes. Biomacromolecules 8, 2366-2373. doi:10.1021/bm070136q

Amrani, S., and Tabrizian, M. (2018). Characterization of Nanoscale Loaded Liposomes Produced by 2D Hydrodynamic Flow Focusing. ACS Biomater. Sci. Eng. 4, 502-513. doi:10.1021/acsbiomaterials.7b00572

Averick, S. E., Magenau, A. J. D., Simakova, A., Woodman, B. F., Seong, A., Mehl, R. A., et al. (2011). Covalently incorporated protein-nanogels using AGET ATRP in an inverse miniemulsion. Polym. Chem. 2, 1476-1478. doi:10.1039/C1PY00050K

Azadi, A., Hamidi, M., Khoshayand, M.-R., Amini, M., and Rouini, M.-R. (2012). Preparation and optimization of surface-treated methotrexate-loaded nanogels intended for brain delivery. Carbohydr. Polym. 90, 462-471. doi:10.1016/ j.carbpol.2012.05.066

Bakó, J., Kerényi, F., Hrubi, E., Varga, I., Daróczi, L., Dienes, B., et al. (2016). Poly- $\gamma$-Glutamic Acid Nanoparticles Based Visible Light-Curable Hydrogel for Biomedical Application. J. Nanomater. 2016, 1-10. doi:10.1155/2016/7350516

Brannigan, R. P., and Khutoryanskiy, V. V. (2017). Synthesis and evaluation of mucoadhesive acryloyl-quaternized PDMAEMA nanogels for ocular drug delivery. Colloids Surf. B: Biointerfaces 155, 538-543. doi:10.1016/j.colsurfb.2017.04.050

Cai, H., Ni, C., and Zhang, L. (2012). Preparation of complex nano-particles based on alginic acid/poly[(2-dimethylamino) ethyl methacrylate] and a drug vehicle for doxorubicin release controlled by ionic strength. Eur. J. Pharm. Sci. 45, 43-49. doi:10.1016/j.ejps.2011.10.020

Chattopadhyay, S., Heine, E., Mourran, A., Richtering, W., Keul, H., and Möller, M. (2016). Waterborne physically crosslinked antimicrobial nanogels. Polym. Chem. 7, 364-369. doi:10.1039/C5PY01566A

Chen, S., Bian, Q., Wang, P., Zheng, X., Lv, L., Dang, Z., et al. (2017). Photo, pH and redox multi-responsive nanogels for drug delivery and fluorescence cell imaging. Polym. Chem. 8, 6150-6157. doi:10.1039/c7py01424d

Chen, X., Chen, L., Yao, X., Zhang, Z., He, C., Zhang, J., et al. (2014). Dual responsive supramolecular nanogels for intracellular drug delivery. Chem. Commun. 50, 3789-3791. doi:10.1039/c4cc00016a

Clegg, J. R., Ludolph, C. M., and Peppas, N. A. (2020). QCM-D assay for quantifying the swelling, biodegradation, and protein adsorption of intelligent nanogels. J. Appl. Polym. Sci. 137, 48655. doi:10.1002/app.48655

Cuggino, J. C., Blanco, E. R. O., Gugliotta, L. M., Alvarez Igarzabal, C. I., and Calderón, M. (2019). Crossing biological barriers with nanogels to improve drug delivery performance. J. Controlled Release 307, 221-246. doi:10.1016/ j.jconrel.2019.06.005

Ding, Y.-F., Wei, J., Li, S., Pan, Y.-T., Wang, L.-H., and Wang, R. (2019a). HostGuest Interactions Initiated Supramolecular Chitosan Nanogels for Selective Intracellular Drug Delivery. ACS Appl. Mater. Inter. 11, 28665-28670. doi:10.1021/acsami.9b09059

Ding, Y.-F., Wei, J., Li, S., Pan, Y.-T., Wang, L.-H., and Wang, R. (2019b). HostGuest Interactions Initiated Supramolecular Chitosan Nanogels for Selective Intracellular Drug Delivery. ACS Appl. Mater. Inter. 11, 28665-28670. doi:10.1021/acsami.9b09059

Dong, S., Jiang, Y., Qin, G., Liu, L., and Zhao, H. (2020). Methionine-Based pH and Oxidation Dual-Responsive Block Copolymer: Synthesis and Fabrication of
Protein Nanogels. Biomacromolecules 21, 4063-4075. doi:10.1021/ acs.biomac.0c00879

Dreiss, C. A. (2020). Hydrogel design strategies for drug delivery. Curr. Opin. Colloid Interf. Sci. 48, 1-17. doi:10.1016/j.cocis.2020.02.001

Feng, Q., Zhang, L., Liu, C., Li, X., Hu, G., Sun, J., et al. (2015). Microfluidic based high throughput synthesis of lipid-polymer hybrid nanoparticles with tunable diameters. Biomicrofluidics 9, 052604. doi:10.1063/1.4922957

Feng, X., Lv, F., Liu, L., Tang, H., Xing, C., Yang, Q., et al. (2010). Conjugated Polymer Nanoparticles for Drug Delivery and Imaging. ACS Appl. Mater. Inter. 2, 2429-2435. doi:10.1021/am100435k

Fu, A., Gwon, K., Kim, M., Tae, G., and Kornfield, J. A. (2015). Visible-lightinitiated thiol-acrylate photopolymerization of heparin-based hydrogels. Biomacromolecules 16, 497-506. doi:10.1021/bm501543a

Gao, Y., Zhou, D., Lyu, J., Matyjaszewski, K., Tai, H., Newland, B., et al. (2020). Complex polymer architectures through free-radical polymerization of multivinyl monomers. Nat. Rev. Chem. 4, 194-212. doi:10.1038/s41570-020-0170-7

Gurnani, P., and Perrier, S. (2020). Controlled radical polymerization in dispersed systems for biological applications. Prog. Polym. Sci. 102, 101209. doi:10.1016/ j.progpolymsci.2020.101209

Hailemeskel, B. Z., Addisu, K. D., Prasannan, A., Mekuria, S. L., Kao, C.-Y., and Tsai, H.-C. (2018). Synthesis and characterization of diselenide linked poly(ethylene glycol) nanogel as multi-responsive drug carrier. Appl. Surf. Sci. 449, 15-22. doi:10.1016/j.apsusc.2017.12.058

Hajebi, S., Abdollahi, A., Roghani-Mamaqani, H., and Salami-Kalajahi, M. (2020). Temperature-Responsive Poly(N-Isopropylacrylamide) Nanogels: The Role of Hollow Cavities and Different Shell Cross-Linking Densities on Doxorubicin Loading and Release. Langmuir 36, 2683-2694. doi:10.1021/ acs.langmuir.9b03892

Hajebi, S., Rabiee, N., Bagherzadeh, M., Ahmadi, S., Rabiee, M., RoghaniMamaqani, H., et al. (2019a). Stimulus-responsive polymeric nanogels as smart drug delivery systems. Acta Biomater. 92, 1-18. doi:10.1016/ j.actbio.2019.05.018

Hajebi, S., Rabiee, N., Bagherzadeh, M., Ahmadi, S., Rabiee, M., RoghaniMamaqani, H., et al. (2019b). Stimulus-responsive polymeric nanogels as smart drug delivery systems. Acta Biomater. 92, 1-18. doi:10.1016/ j.actbio.2019.05.018

Huang, K., He, Y., Zhu, Z., Guo, J., Wang, G., Deng, C., et al. (2019). Small, Traceable, Endosome-Disrupting, and Bioresponsive Click Nanogels Fabricated via Microfluidics for CD44-Targeted Cytoplasmic Delivery of Therapeutic Proteins. ACS Appl. Mater. Inter. 11, 22171-22180. doi:10.1021/ acsami.9b05827

Iqbal, S., Blenner, M., Alexander-Bryant, A., and Larsen, J. (2020). Polymersomes for Therapeutic Delivery of Protein and Nucleic Acid Macromolecules: From Design to Therapeutic Applications. Biomacromolecules 21, 1327-1350. doi:10.1021/acs.biomac.9b01754

Ji, P., Zhou, B., Zhan, Y., Wang, Y., Zhang, Y., Li, Y., et al. (2017). Multistimulative Nanogels with Enhanced Thermosensitivity for Intracellular Therapeutic Delivery. ACS Appl. Mater. Inter. 9, 39143-39151. doi:10.1021/acsami.7b08209

Kim, H., Kim, B., Lee, C., Ryu, J. L., Hong, S.-J., Kim, J., et al. (2016). Redoxresponsive biodegradable nanogels for photodynamic therapy using Chlorin e6. J. Mater. Sci. 51, 8442-8451. doi:10.1007/s10853-016-0104-4

Kumar, P., Liu, B., and Behl, G. (2019). A Comprehensive Outlook of Synthetic Strategies and Applications of Redox-Responsive Nanogels in Drug Delivery. Macromol. Biosci. 19, 1900071. doi:10.1002/mabi.201900071

Lakkakula, J. R., Gujarathi, P., Pansare, P., and Tripathi, S. (2021). A comprehensive review on alginate-based delivery systems for the delivery of chemotherapeutic agent: Doxorubicin. Carbohydr. Polym. 259, 117696. doi:10.1016/j.carbpol.2021.117696

Lanfear, J., Fleming, J., Wu, L., Webster, G., and Harrison, P. R. (1994). The selenium metabolite selenodiglutathione induces p53 and apoptosis: relevance to the chemopreventive effects of selenium. Carcinogenesis 15, 1387-1392. doi:10.1093/carcin/15.7.1387

Large, D. E., Abdelmessih, R. G., Fink, E. A., and Auguste, D. T. (2021). Liposome composition in drug delivery design, synthesis, characterization, and clinical application. Adv. Drug Deliv. Rev. 176, 113851. doi:10.1016/j.addr.2021.113851

Le, C. M. Q., Cao, X. T., Tu, T. T. K., Gal, Y.-S., and Lim, K. T. (2018). Facile approach to prepare $\mathrm{pH}$ and redox-responsive nanogels via Diels-Alder click reaction. Express Polym. Lett. 12, 688-698. doi:10.3144/expresspolymlett.2018.59 
Lee, J., Lee, C., Kim, T. H., Lee, E. S., Shin, B. S., Chi, S.-C., et al. (2012). Selfassembled glycol chitosan nanogels containing palmityl-acylated exendin- 4 peptide as a long-acting anti-diabetic inhalation system. J. Controlled Release 161, 728-734. doi:10.1016/j.jconrel.2012.05.029

Lee, S. J., Koo, H., Jeong, H., Huh, M. S., Choi, Y., Jeong, S. Y., et al. (2011). Comparative study of photosensitizer loaded and conjugated glycol chitosan nanoparticles for cancer therapy. J. Controlled Release 152, 21-29. doi:10.1016/ j.jconrel.2011.03.027

Le Quéméner, F., Subervie, D., Morlet-Savary, F., Lalevée, J., Lansalot, M., Bourgeat-Lami, E., et al. (2018). Visible-Light Emulsion Photopolymerization of Styrene. Angew. Chem. Int. Ed. 57, 957-961. doi:10.1002/anie.201710488

Li, C., Huang, W., Zhou, L., Huang, P., Pang, Y., Zhu, X., et al. (2015a). PEGylated poly(diselenide-phosphate) nanogel as efficient self-delivery nanomedicine for cancer therapy. Polym. Chem. 6, 6498-6508. doi:10.1039/c5py00995b

Li, C., Liu, X., Liu, Y., Huang, F., Wu, G., Liu, Y., et al. (2019a). Glucose and $\mathrm{H} 2 \mathrm{O} 2$ dual-sensitive nanogels for enhanced glucose-responsive insulin delivery. Nanoscale 11, 9163-9175. doi:10.1039/c9nr01554j

Li, D., van Nostrum, C. F., Mastrobattista, E., Vermonden, T., and Hennink, W. E. (2017). Nanogels for intracellular delivery of biotherapeutics. J. Controlled Release 259, 16-28. doi:10.1016/j.jconrel.2016.12.020

$\mathrm{Li}$, J., and Liu, P. (2018). One-pot fabrication of pH/reduction dual-stimuli responsive chitosan-based supramolecular nanogels for leakage-free tumorspecific DOX delivery with enhanced anti-cancer efficacy. Carbohydr. Polym. 201, 583-590. doi:10.1016/j.carbpol.2018.08.102

Li, J., Peng, Y., Peña, J., and Xing, J. (2021a). An initiating system with high efficiency for PEGDA photopolymerization at $532 \mathrm{~nm}$. J. Photochem. Photobiol. A: Chem. 411, 113216. doi:10.1016/j.jphotochem.2021.113216

Li, X., Sun, H., Li, H., Hu, C., Luo, Y., Shi, X., et al. (2021b). Multi-Responsive Biodegradable Cationic Nanogels for Highly Efficient Treatment of Tumors. Adv. Funct. Mater. 31, 2100227. doi:10.1002/adfm.202100227

Li, Y., Ding, J., Zhu, J., Tian, H., and Chen, X. (2018). Photothermal EffectTriggered Drug Release from Hydrogen Bonding-Enhanced Polymeric Micelles. Biomacromolecules 19, 1950-1958. doi:10.1021/acs.biomac.7b01702

Li, Y., Maciel, D., Rodrigues, J., Shi, X., and Tomás, H. (2015b). Biodegradable Polymer Nanogels for Drug/Nucleic Acid Delivery. Chem. Rev. 115, 8564-8608. doi:10.1021/cr500131f

Li, Z., Huang, J., and Wu, J. (2021c). pH-Sensitive nanogels for drug delivery in cancer therapy. Biomater. Sci. 9, 574-589. doi:10.1039/d0bm01729a

Li, Z., Van Zee, N. J., Bates, F. S., and Lodge, T. P. (2019b). Polymer Nanogels as Reservoirs To Inhibit Hydrophobic Drug Crystallization. Acs Nano 13, 1232-1243. doi:10.1021/acsnano.8b06393

Liang, J., Ma, Y., Sims, S., and Wu, L. (2015). A patterned porous polymer film for localized capture of insulin and glucose-responsive release. J. Mater. Chem. B 3, 1281-1288. doi:10.1039/C4TB01537A

Liu, Q., Peña, J., and Xing, J. (2021). Rapid preparation of nanogels by photopolymerization at $532 \mathrm{~nm}$. Colloids Surf. B: Biointerfaces 206, 111943. doi:10.1016/j.colsurfb.2021.111943

Lou, S., Gao, S., Wang, W., Zhang, M., Zhang, J., Wang, C., et al. (2015). Galactosefunctionalized multi-responsive nanogels for hepatoma-targeted drug delivery. Nanoscale 7, 3137-3146. doi:10.1039/c4nr06714b

Lou, S., Zhang, X., Zhang, M., Ji, S., Wang, W., Zhang, J., et al. (2017). Preparation of a dual cored hepatoma-specific star glycopolymer nanogel via arm-first ATRP approach. Ijn Vol. 12, 3653-3664. doi:10.2147/ijn.S134367

Lovell, P. A., and Schork, F. J. (2020). Fundamentals of Emulsion Polymerization. Biomacromolecules 21, 4396-4441. doi:10.1021/acs.biomac.0c00769

Lu, Y., Jia, D., Ma, X., Liang, M., Hou, S., Qiu, W., et al. (2021). Reduction-Responsive Chemo-Capsule-Based Prodrug Nanogel for Synergistic Treatment of Tumor Chemotherapy. ACS Appl. Mater. Inter. 13, 8940-8951. doi:10.1021/acsami.0c21710

Luan, S., Zhu, Y., Wu, X., Wang, Y., Liang, F., and Song, S. (2017). HyaluronicAcid-Based pH-Sensitive Nanogels for Tumor-Targeted Drug Delivery. ACS Biomater. Sci. Eng. 3, 2410-2419. doi:10.1021/acsbiomaterials.7b00444

Luckanagul, J. A., Pitakchatwong, C., Ratnatilaka Na Bhuket, P., Muangnoi, C., Rojsitthisak, P., Chirachanchai, S., et al. (2018a). Chitosan-based polymer hybrids for thermo-responsive nanogel delivery of curcumin. Carbohydr. Polym. 181, 1119-1127. doi:10.1016/j.carbpol.2017.11.027

Luckanagul, J. A., Pitakchatwong, C., Ratnatilaka Na Bhuket, P., Muangnoi, C., Rojsitthisak, P., Chirachanchai, S., et al. (2018b). Chitosan-based polymer hybrids for thermo-responsive nanogel delivery of curcumin. Carbohydr. Polym. 181, 1119-1127. doi:10.1016/j.carbpol.2017.11.027

Ma, X., Zhang, T., Qiu, W., Liang, M., Gao, Y., Xue, P., et al. (2021). Bioresponsive prodrug nanogel-based polycondensate strategy deepens tumor penetration and potentiates oxidative stress. Chem. Eng. J. 420, 127657. doi:10.1016/ j.cej.2020.127657

Mackiewicz, M., Romanski, J., Krug, P., Mazur, M., Stojek, Z., and Karbarz, M. (2019). Tunable environmental sensitivity and degradability of nanogels based on derivatives of cystine and poly(ethylene glycols) of various length for biocompatible drug carrier. Eur. Polym. J. 118, 606-613. doi:10.1016/ j.eurpolymj.2019.06.031

Mahmoudi, Z., Mohammadnejad, J., Razavi Bazaz, S., Abouei Mehrizi, A., Saidijam, M., Dinarvand, R., et al. (2020). Promoted chondrogenesis of hMCSs with controlled release of TGF- $\beta 3$ via microfluidics synthesized alginate nanogels. Carbohydr. Polym. 229, 115551. doi:10.1016/ j.carbpol.2019.115551

Maiti, D., Chao, Y., Dong, Z., Yi, X., He, J., Liu, Z., et al. (2018). Development of a thermosensitive protein conjugated nanogel for enhanced radio-chemotherapy of cancer. Nanoscale 10, 13976-13985. doi:10.1039/c8nr03986k

Manchun, S., Cheewatanakornkool, K., Dass, C. R., and Sriamornsak, P. (2014). Novel $\mathrm{pH}$-responsive dextrin nanogels for doxorubicin delivery to cancer cells with reduced cytotoxicity to cardiomyocytes and stem cells. Carbohydr. Polym. 114, 78-86. doi:10.1016/j.carbpol.2014.08.002

Manchun, S., Dass, C. R., Cheewatanakornkool, K., and Sriamornsak, P. (2015). Enhanced anti-tumor effect of $\mathrm{pH}$-responsive dextrin nanogels delivering doxorubicin on colorectal cancer. Carbohydr. Polym. 126, 222-230. doi:10.1016/j.carbpol.2015.03.018

Matsui, J. K., Lang, S. B., Heitz, D. R., and Molander, G. A. (2017). PhotoredoxMediated Routes to Radicals: The Value of Catalytic Radical Generation in Synthetic Methods Development. ACS Catal. 7, 2563-2575. doi:10.1021/ acscatal.7b00094

Matyjaszewski, K., and Xia, J. (2001). Atom Transfer Radical Polymerization. Chem. Rev. 101, 2921-2990. doi:10.1021/cr940534g

Mauri, E., Perale, G., and Rossi, F. (2018). Nanogel Functionalization: A Versatile Approach To Meet the Challenges of Drug and Gene Delivery. ACS Appl. Nano Mater. 1, 6525-6541. doi:10.1021/acsanm.8b01686

Messager, L., Portecop, N., Hachet, E., Lapeyre, V., Pignot-Paintrand, I., Catargi, B., et al. (2013). Photochemical crosslinking of hyaluronic acid confined in nanoemulsions: towards nanogels with a controlled structure. J. Mater. Chem. B 1, 3369-3379. doi:10.1039/c3tb20300j

Mohammadi, M., Arabi, L., and Alibolandi, M. (2020). Doxorubicin-loaded composite nanogels for cancer treatment. J. Controlled Release 328, 171-191. doi:10.1016/j.jconrel.2020.08.033

Mondal, P., Behera, P. K., and Singha, N. K. (2021). Macromolecular engineering in functional polymers via 'click chemistry' using triazolinedione derivatives. Prog. Polym. Sci. 113, 101343. doi:10.1016/j.progpolymsci.2020.101343

Neamtu, I., Rusu, A. G., Diaconu, A., Nita, L. E., and Chiriac, A. P. (2017). Basic concepts and recent advances in nanogels as carriers for medical applications. Drug Deliv. 24, 539-557. doi:10.1080/10717544.2016.1276232

Nie, M., Zheng, M., Li, C., Shen, F., Liu, M., Luo, H., et al. (2019). Assembled Step Emulsification Device for Multiplex Droplet Digital Polymerase Chain Reaction. Anal. Chem. 91, 1779-1784. doi:10.1021/acs.analchem.8b04313

Noordergraaf, I.-W., Fourie, T., and Raffa, P. (2018). Free-Radical Graft Polymerization onto Starch as a Tool to Tune Properties in Relation to Potential Applications. A Review. A ReviewProcesses 6, 31. doi:10.3390/ pr6040031

Oh, J. K., Drumright, R., Siegwart, D. J., and Matyjaszewski, K. (2008). The development of microgels/nanogels for drug delivery applications. Prog. Polym. Sci. 33, 448-477. doi:10.1016/j.progpolymsci.2008.01.002

Oh, J. K., Siegwart, D. J., Lee, H.-i., Sherwood, G., Peteanu, L., Hollinger, J. O., et al. (2007). Biodegradable Nanogels Prepared by Atom Transfer Radical Polymerization as Potential Drug Delivery Carriers: Synthesis, Biodegradation, in Vitro Release, and Bioconjugation. J. Am. Chem. Soc. 129, 5939-5945. doi:10.1021/ja0691501

Pei, M., Jia, X., Zhao, X., Li, J., and Liu, P. (2018). Alginate-based cancer-associated, stimuli-driven and turn-on theranostic prodrug nanogel for cancer detection and treatment. Carbohydr. Polym. 183, 131-139. doi:10.1016/ j.carbpol.2017.12.013 
Peng, J., Qi, T., Liao, J., Chu, B., Yang, Q., Li, W., et al. (2013). Controlled release of cisplatin from $\mathrm{pH}$-thermal dual responsive nanogels. Biomaterials 34, 8726-8740. doi:10.1016/j.biomaterials.2013.07.092

Peng, Y., Wang, Z., Peña, J., Guo, Z., and Xing, J. (2021). Effect of TEOA on the Process of Photopolymerization at $532 \mathrm{~nm}$ and Properties of Nanogels. Photochem. Photobiol. doi:10.1111/php.13505

Pereira, S. O., Trindade, T., and Barros-Timmons, A. (2020). Biofunctional Polymer Coated Au Nanoparticles Prepared via RAFT-Assisted Encapsulating Emulsion Polymerization and Click Chemistry. Polymers 12, 1442. doi:10.3390/polym 12071442

Pérez-Álvarez, L., Manuel Laza, J., and Álvarez-Bautista, A. (2016). Covalently and Ionically Crosslinked Chitosan Nanogels for Drug Delivery. Cpd 22, 3380-3398. doi:10.2174/1381612822666160216152008

Phan, Q. T., Patil, M. P., Tu, T. T. K., Kim, G.-D., and Lim, K. T. (2020). Synthesis of zwitterionic redox-responsive nanogels by one-pot amine-thiol-ene reaction for anticancer drug release application. Reactive Funct. Polym. 147, 104463. doi:10.1016/j.reactfunctpolym.2019.104463

Pinelli, F., Ortolà, Ó. F., Makvandi, P., Perale, G., and Rossi, F. (2020). In vivo drug delivery applications of nanogels: a review. Nanomedicine 15, 2707-2727. doi:10.2217/nnm-2020-0274

Pu, X.-Q., Ju, X.-J., Zhang, L., Cai, Q.-W., Liu, Y.-Q., Peng, H.-Y., et al. (2021). Novel Multifunctional Stimuli-Responsive Nanoparticles for Synergetic Chemo-Photothermal Therapy of Tumors. ACS Appl. Mater. Inter. 13, 28802-28817. doi:10.1021/acsami.1c05330

Qin, B., Yin, Z., Tang, X., Zhang, S., Wu, Y., Xu, J.-F., et al. (2020). Supramolecular polymer chemistry: From structural control to functional assembly. Prog. Polym. Sci. 100, 101167. doi:10.1016/j.progpolymsci.2019.101167

Qu, J.-B., Chapman, R., Chen, F., Lu, H., and Stenzel, M. H. (2017). Swollen Micelles for the Preparation of Gated, Squeezable, pH-Responsive Drug Carriers. ACS Appl. Mater. Inter. 9, 13865-13874. doi:10.1021/acsami.7b01120

Qu, Y., Chu, B., Wei, X., Lei, M., Hu, D., Zha, R., et al. (2019). Redox/pH dualstimuli responsive camptothecin prodrug nanogels for "on-demand" drug delivery. J. Controlled Release 296, 93-106. doi:10.1016/j.jconrel.2019.01.016

Raemdonck, K., Demeester, J., and De Smedt, S. (2009). Advanced nanogel engineering for drug delivery. Soft Matter 5, 707-715. doi:10.1039/b811923f

Rhee, M., Valencia, P. M., Rodriguez, M. I., Langer, R., Farokhzad, O. C., and Karnik, R. (2011). Synthesis of Size-Tunable Polymeric Nanoparticles Enabled by 3D Hydrodynamic Flow Focusing in Single-Layer Microchannels. Adv. Mater. 23, H79-H83. doi:10.1002/adma.201004333

Sahle, F. F., Giulbudagian, M., Bergueiro, J., Lademann, J., and Calderón, M. (2017). Dendritic polyglycerol and $\mathrm{N}$-isopropylacrylamide based thermoresponsive nanogels as smart carriers for controlled delivery of drugs through the hair follicle. Nanoscale 9, 172-182. doi:10.1039/c6nr06435c

Seidi, F., Jenjob, R., and Crespy, D. (2018). Designing Smart Polymer Conjugates for Controlled Release of Payloads. Chem. Rev. 118, 3965-4036. doi:10.1021/ acs.chemrev.8b00006

Sengel, S. B., and Sahiner, N. (2019). Synthesis and characterization of poly(N-(2mercaptoethyl) acrylamide) microgel for biomedical applications. Polym. Adv. Technol. 30, 2109-2121. doi:10.1002/pat.4644

Senthilkumar, T., Lv, F., Zhao, H., Liu, L., and Wang, S. (2019). Conjugated Polymer Nanogel Binding Anticancer Drug through Hydrogen Bonds for Sustainable Drug Delivery. ACS Appl. Bio Mater. 2, 6012-6020. doi:10.1021/ acsabm.9b00941

Seo, S., Lee, C.-S., Jung, Y.-S., and Na, K. (2012). Thermo-sensitivity and triggered drug release of polysaccharide nanogels derived from pullulan-g-poly(l-lactide) copolymers. Carbohydr. Polym. 87, 1105-1111. doi:10.1016/ j.carbpol.2011.08.061

Shah, S., Rangaraj, N., Laxmikeshav, K., and Sampathi, S. (2020). "Nanogels as drug carriers - Introduction, chemical aspects, release mechanisms and potential applications". Int. J. Pharmaceutics 581, 119268. doi:10.1016/ j.ijpharm.2020.119268

Sharma, A., Garg, T., Aman, A., Panchal, K., Sharma, R., Kumar, S., et al. (2016). Nanogel-an advanced drug delivery tool: Current and future. Artif. Cell Nanomedicine, Biotechnol. 44, 165-177. doi:10.3109/21691401.2014.930745

Siegwart, D. J., Srinivasan, A., Bencherif, S. A., Karunanidhi, A., Oh, J. K., Vaidya, S., et al. (2009). Cellular Uptake of Functional Nanogels Prepared by Inverse Miniemulsion ATRP with Encapsulated Proteins, Carbohydrates, and Gold Nanoparticles. Biomacromolecules 10, 2300-2309. doi:10.1021/bm9004904
Su, H., Jia, Q., and Shan, S. (2016). Synthesis and characterization of Schiff base contained dextran microgels in water-in-oil inverse microemulsion. Carbohydr. Polym. 152, 156-162. doi:10.1016/j.carbpol.2016.06.091

Su, H., Zhang, W., Wu, Y., Han, X., Liu, G., Jia, Q., et al. (2018). Schiff basecontaining dextran nanogel as pH-sensitive drug delivery system of doxorubicin: Synthesis and characterization. J. Biomater. Appl. 33, 170-181. doi:10.1177/0885328218783969

Sun, Z., Yi, Z., Zhang, H., Ma, X., Su, W., Sun, X., et al. (2017). Bio-responsive alginate-keratin composite nanogels with enhanced drug loading efficiency for cancer therapy. Carbohydr. Polym. 175, 159-169. doi:10.1016/ j.carbpol.2017.07.078

Tai, W., Mo, R., Lu, Y., Jiang, T., and Gu, Z. (2014). Folding graft copolymer with pendant drug segments for co-delivery of anticancer drugs. Biomaterials 35 , 7194-7203. doi:10.1016/j.biomaterials.2014.05.004

Tasdelen, M. A., Kiskan, B., and Yagci, Y. (2016). Externally stimulated click reactions for macromolecular syntheses. Prog. Polym. Sci. 52, 19-78. doi:10.1016/j.progpolymsci.2015.09.003

Thelu, H. V. P., Albert, S. K., Golla, M., Krishnan, N., Ram, D., Srinivasula, S. M., et al. (2018). Size controllable DNA nanogels from the self-assembly of DNA nanostructures through multivalent host-guest interactions. Nanoscale 10, 222-230. doi:10.1039/c7nr06985e

Theune, L. E., Buchmann, J., Wedepohl, S., Molina, M., Laufer, J., and Calderón, M. (2019). NIR- and thermo-responsive semi-interpenetrated polypyrrole nanogels for imaging guided combinational photothermal and chemotherapy. J. Controlled Release 311-312, 147-161. doi:10.1016/ j.jconrel.2019.08.035

Tian, Y., Tian, R., Chen, L., Jin, R., Feng, Y., Bai, Y., et al. (2019). Redox-Responsive Nanogel with Intracellular Reconstruction and Programmable Drug Release for Targeted Tumor Therapy. Macromol. Rapid Commun. 40, 1800824. doi:10.1002/marc.201800824

Ulukan, H., and Swaan, P. W. (2002). Camptothecins. Drugs 62, 2039-2057. doi:10.2165/00003495-200262140-00004

Wang, H., Ke, F., Mararenko, A., Wei, Z., Banerjee, P., and Zhou, S. (2014). Responsive polymer-fluorescent carbon nanoparticle hybrid nanogels for optical temperature sensing, near-infrared light-responsive drug release, and tumor cell imaging. Nanoscale 6, 7443-7452. doi:10.1039/c4nr01030b

Wang, S., Ha, Y., Huang, X., Chin, B., Sim, W., and Chen, R. (2018). A New Strategy for Intestinal Drug Delivery via $\mathrm{pH}$-Responsive and Membrane-Active Nanogels. ACS Appl. Mater. Inter. 10, 36622-36627. doi:10.1021/ acsami.8b15661

Wang, X., Peng, Y., Peña, J., and Xing, J. (2021). Preparation of ultrasmall nanogels by facile emulsion-free photopolymerization at $532 \mathrm{~nm}$. J. Colloid Interf. Sci. 582, 711-719. doi:10.1016/j.jcis.2020.08.056

Wang, Y., Zheng, J., Tian, Y., and Yang, W. (2015). Acid degradable poly(vinylcaprolactam)-based nanogels with ketal linkages for drug delivery. J. Mater. Chem. B 3, 5824-5832. doi:10.1039/c5tb00703h

Wang, Y., Zu, M., Ma, X., Jia, D., Lu, Y., Zhang, T., et al. (2020). GlutathioneResponsive Multifunctional "Trojan Horse" Nanogel as a Nanotheranostic for Combined Chemotherapy and Photodynamic Anticancer Therapy. ACS Appl. Mater. Inter. 12, 50896-50908. doi:10.1021/acsami.0c15781

Webber, M. J., Appel, E. A., Meijer, E. W., and Langer, R. (2016). Supramolecular biomaterials. Nat. Mater 15, 13-26. doi:10.1038/nmat4474

Wei, X., Senanayake, T. H., Warren, G., and Vinogradov, S. V. (2013). Hyaluronic acid-based nanogel-drug conjugates with enhanced anticancer activity designed for the targeting of CD44-positive and drug-resistant tumors. Bioconjug. Chem. 24, 658-668. doi:10.1021/bc300632w

Wu, C., Hu, W., Wei, Q., Qiao, L., Gao, Y., Lv, Y., et al. (2018). Controllable Growth of Core-Shell Nanogels via Esterase-Induced Self-Assembly of Peptides for Drug Delivery. J Biomed. Nanotechnol 14, 354-361. doi:10.1166/jbn.2018.2492

Wu, W.-S. (2006). The signaling mechanism of ROS in tumor progression. Cancer Metastasis Rev. 25, 695-705. doi:10.1007/s10555-006-9037-8

Xiao, K., Li, Y., Luo, J., Lee, J. S., Xiao, W., Gonik, A. M., et al. (2011). The effect of surface charge on in vivo biodistribution of PEG-oligocholic acid based micellar nanoparticles. Biomaterials 32, 3435-3446. doi:10.1016/j.biomaterials.2011.01.021

Xin, F., Wei, M., Jiang, S., Gao, Y., Nie, J., Wu, Y., et al. (2020). Design of hydrophilic photocleavage o-nitrobenzyl acrylate-modified nanogels with outstanding biocompatibility prepared by RAFT polymerization for drug carrier. Eur. Polym. J. 122, 109364. doi:10.1016/j.eurpolymj.2019.109364 
Xu, S., Olenyuk, B. Z., Okamoto, C. T., and Hamm-Alvarez, S. F. (2013). Targeting receptor-mediated endocytotic pathways with nanoparticles: Rationale and advances. Adv. Drug Deliv. Rev. 65, 121-138. doi:10.1016/ j.addr.2012.09.041

Yang, H., Wang, Q., Huang, S., Xiao, A., Li, F., Gan, L., et al. (2016). Smart pH/Redox Dual-Responsive Nanogels for On-Demand Intracellular Anticancer Drug Release. ACS Appl. Mater. Inter. 8, 7729-7738. doi:10.1021/acsami.6b01602

Yoon, H. Y., Koo, H., Choi, K. Y., Lee, S. J., Kim, K., Kwon, I. C., et al. (2012). Tumor-targeting hyaluronic acid nanoparticles for photodynamic imaging and therapy. Biomaterials 33, 3980-3989. doi:10.1016/j.biomaterials.2012.02.016

Yu, Y., Cheng, Y., Tong, J., Zhang, L., Wei, Y., and Tian, M. (2021). Recent advances in thermo-sensitive hydrogels for drug delivery. J. Mater. Chem. B 9, 2979-2992. doi:10.1039/d0tb02877k

Yuan, D., Ding, L., Sun, Z., and Li, X. (2018). MRI/Fluorescence bimodal amplification system for cellular GSH detection and tumor cell imaging based on manganese dioxide nanosheet. Sci. Rep. 8, 1747. doi:10.1038/s41598-018-20110-Z

Zan, M., Li, J., Huang, M., Lin, S., Luo, D., Luo, S., et al. (2015). Near-infrared lighttriggered drug release nanogels for combined photothermal-chemotherapy of cancer. Biomater. Sci. 3, 1147-1156. doi:10.1039/c5bm00048c

Zavgorodnya, O., Carmona-Moran, C. A., Kozlovskaya, V., Liu, F., Wick, T. M., and Kharlampieva, E. (2017). Temperature-responsive nanogel multilayers of poly(N-vinylcaprolactam) for topical drug delivery. J. Colloid Interf. Sci. 506, 589-602. doi:10.1016/j.jcis.2017.07.084

Zhang, L., Chen, Q., Ma, Y., and Sun, J. (2020). Microfluidic Methods for Fabrication and Engineering of Nanoparticle Drug Delivery Systems. ACS Appl. Bio Mater. 3, 107-120. doi:10.1021/acsabm.9b00853

Zhang, Y., Andrén, O. C. J., Nordström, R., Fan, Y., Malmsten, M., Mongkhontreerat, S., et al. (2019). Off-Stoichiometric Thiol-Ene Chemistry to Dendritic Nanogel Therapeutics. Adv. Funct. Mater. 29, 1806693. doi:10.1002/adfm.201806693

Zhang, Y., Ma, C., Zhang, S., Wei, C., Xu, Y., and Lu, W. (2018). ROS-responsive selenium-containing polyphosphoester nanogels for activated anticancer drug release. Mater. Today Chem. 9, 34-42. doi:10.1016/j.mtchem.2018.04.002
Zhao, G., Long, L., Zhang, L., Peng, M., Cui, T., Wen, X., et al. (2017). Smart pHsensitive nanoassemblies with cleavable PEGylation for tumor targeted drug delivery. Sci. Rep. 7, 3383. doi:10.1038/s41598-017-03111-2

Zhao, Q., Zhang, S., Wu, F., Li, D., Zhang, X., Chen, W., et al. (2021). Rational Design of Nanogels for Overcoming the Biological Barriers in Various Administration Routes. Angew. Chem. Int. Ed. 60, 14760-14778. doi:10.1002/anie.201911048

Zhu, J.-Y., Lei, Q., Yang, B., Jia, H.-Z., Qiu, W.-X., Wang, X., et al. (2015). Efficient nuclear drug translocation and improved drug efficacy mediated by acidityresponsive boronate-linked dextran/cholesterol nanoassembly. Biomaterials 52, 281-290. doi:10.1016/j.biomaterials.2015.02.048

Zhu, Y., Yang, B., Chen, S., and Du, J. (2017). Polymer vesicles: Mechanism, preparation, application, and responsive behavior. Prog. Polym. Sci. 64, 1-22. doi:10.1016/j.progpolymsci.2015.05.001

Zhu, Z., Kimura, M., Itokawa, Y., Aoki, T., Takahashi, J. A., Nakatsu, S., et al. (1996). Apoptosis induced by selenium in human glioma cell lines. Biol. Trace Elem. Res. 54, 123-134. doi:10.1007/BF02786259

Conflict of Interest: The authors declare that the research was conducted in the absence of any commercial or financial relationships that could be construed as a potential conflict of interest.

Publisher's Note: All claims expressed in this article are solely those of the authors and do not necessarily represent those of their affiliated organizations, or those of the publisher, the editors and the reviewers. Any product that may be evaluated in this article, or claim that may be made by its manufacturer, is not guaranteed or endorsed by the publisher.

Copyright (C) 2021 Du, Gao, Kang and Xing. This is an open-access article distributed under the terms of the Creative Commons Attribution License (CC BY). The use, distribution or reproduction in other forums is permitted, provided the original author(s) and the copyright owner(s) are credited and that the original publication in this journal is cited, in accordance with accepted academic practice. No use, distribution or reproduction is permitted which does not comply with these terms. 